\title{
Learning-dependent Neuronal Activity in the Premotor Cortex: Activity during the Acquisition of Conditional Motor Associations
}

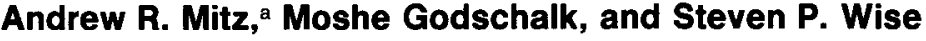 \\ Laboratory of Neurophysiology, National Institute of Mental Health, Poolesville, Maryland 20837
}

\begin{abstract}
It has been proposed that the premotor cortex plays a role in the selection of motor programs based on environmental context. To test this hypothesis, we recorded the activity of single neurons as monkeys learned visuomotor associations. The hypothesis predicts that task-related premotor cortical activity before learning should differ from that afterward. We found that a substantial population of premotor cortex neurons, over half of those adequately tested, showed the predicted learning-dependent changes in activity. The present findings support a role for premotor cortex in motor preparation, generally, and suggest a specific role In the selection of movements on the basis of arbitrary associations.
\end{abstract}

Recent physiological and behavioral investigation indicates that the primate premotor cortex (PM) plays a role in the sensory guidance of movement and some aspect of motor preparation (for review, see Humphrey, 1979; Wiesendanger, 1981; Wise, 1984, 1985a,b; Gentilucci and Rizzolatti, 1989). PM lesions disrupt learning of arbitrary associations between visual stimuli and motor responses, a property that contrasts PM with the primary motor cortex (M1), the prefrontal cortex, and the supplementary motor area (Halsband and Passingham, 1982, 1985; Petrides, 1982, 1985a,b, 1986, 1987; Passingham, 1987, 1988, 1989; Passingham et al., 1989; see also Crowne et al., 1989; Halsband and Freund, 1990). Based on those and other observations, Passingham (1988) hypothesized that PM plays a role in retrieval of movements from memory based on environmental context.

To test this hypothesis, we compared PM activity in two conditions: in one, monkeys selected a response due to an arbitrary association between a visual stimulus and that response; in the other, they selected the same response on some other basis. We trained monkeys to learn new conditional motor associations and to respond before learning what an unfamiliar stimulus instructed them to do. In one condition, when a stimulus was unfamiliar, the monkeys sometimes emitted the correct response by chance. The other condition developed as learning

\footnotetext{
Received Sept. 27, 1990; revised Jan. 11, 1991; accepted Jan. 24, 1991.

We thank D. Gaffan for advice on experimental design and for software development and G. di Pellegrino for assistance in data collection. K. Kurata, R. E. Passingham, M. Petrides, and J. Tanji provided useful comments on the manuscript.

Correspondence should be addressed to Steven P. Wise, Laboratory of Neurophysiology, National Institute of Mental Health, P.O. Box 289, Poolesville, MD 20837.

a Present address: Department of Anatomy, Erasmus University, P.O. Box 1738, 3000 DR Rotterdam, The Netherlands.

Copyright (C) 1991 Society for Neuroscience $0270-6474 / 91 / 111855-18 \$ 03.00 / 0$
}

progressed: the monkeys chose the same movement in response to the identical stimulus, based not on chance but on the learned instructional significance of the stimulus. If PM participates in the selection of movements based on stimulus context, then at least some of its cells should show activity differences between the two conditions. Many do, a result that has been reported previously in preliminary form (Mitz et al., 1989; Wise, 1989).

\section{Materials and Methods}

Subjects and apparatus. Two male rhesus monkeys (Macaca mulatta; 3.3 and $4.3 \mathrm{~kg}$, respectively) served as subjects in this study. Each monkey sat in a primate chair facing a video screen $48 \mathrm{~cm}$ from its head. A spring-loaded handle, at waist level, rested at the center of a T-pattern (Fig. 1). It could be moved $4 \mathrm{~cm}$ to one of three final positions: left, right, or down (toward the monkey). Both monkeys worked with the right forelimb. Three infrared light beams detected when the handle left its central position, and three snap-action switches indicated when the handle reached the limit of each direction of movement. Stimuli were presented on an Enhanced Graphics Display connected to an IBM PC/AT microcomputer, which acted as a slave to the minicomputer (Plessey LSI 11/23) used for data recording.

Behavioral paradigm. After the handle had been centered for $1.0 \mathrm{sec}$, an instruction stimulus (IS) appeared on the previously blank screen (Fig. 1). Each IS consisted of a small $(1.0 \times 1.2 \mathrm{~cm})$ AScII character superimposed on a second one twice its size and of different color (Gaffan and Harrison, 1988). The use of 14 colors yielded approximately $10^{\circ}$ possible unique visual stimuli. Four stimuli served as familiar stimuli, to which each monkey had responded in thousands of training trials before recording began. The microcomputer, using a 16-bit randomnumber algorithm, generated novel stimuli in groups of 100 . Within each group of 100 novel stimuli, no two exactly matched each other or any of the four familiar stimuli.

One IS appeared on each trial. It was chosen from a set of four or eight stimuli presented in a block of trials. Each stimulus set could include any mixture of familiar and novel stimuli, up to the limit of four familiar stimuli. In a typical example, one block of trials had four familiar stimuli; the next block had four novel stimuli. After its initial presentation, the IS remained on the screen for an instructed delay period of $1.0,1.5$, or $3.0 \mathrm{sec}$ (pseudorandomly selected), then disappeared for $100 \mathrm{msec}$ [the trigger signal (TS)], after which it reappeared. The monkey responded to each stimulus by moving the handle to one of the three targets (leftward, downward, or rightward responses) within $1.0 \mathrm{sec}$ of the TS or by withholding handle movement for $1.0 \mathrm{sec}$ after the TS (a no-go response). The animal had to choose one of those four possible responses to each stimulus, and each stimulus was associated with one and only one correct response, which was rewarded. We conditioned the monkey to respond to every presentation of a stimulus, even when the monkey could not know the instructional significance of that stimulus. After a trial in which the monkey chose an incorrect response, the IS presented was repeated for the next trial. When the monkey responded correctly, the computer pseudorandomly selected an IS for the next trial. The present task derives from the learning-set paradigm of Harlow (1949), in which it was shown that animals become progressively better at learning specific discriminations or associations as they gain experience in solving specific "problems" of a general type.

Recording. A stainless-steel recording chamber was implanted over the left frontal lobe. Glass-coated platinum-iridium electrodes with 5- 
15- $\mu \mathrm{m}$ tip exposures registered the single-cell potentials, which wcre discriminated with a time-voltage window discriminator (BAK Instruments, DIS-1). For most neurons, the discriminated waveform was stored shortly after isolation (Data Precision 6000 waveform analyzer), for comparison with subsequently discriminated potentials from the same neuron.

Surface electrodes monitored electromyographic (EMG) activity at the end of the recording sessions for each monkey. The groups of muscles sampled bilaterally in the first monkey consisted of deltoid, a group of wrist extensors, infraspinatus, and triceps. Additionally, we monitored latissimus dorsi, a group of wrist flexors, biceps, trapezius, cervical paravertebral muscles, pectoralis major, gluteus maximus, temporalis, vastus lateralis and medialis, gastrocnemius, extensor digitorum longus, sternocleidomastoid, and obicularis orbis ipsilateral to the performing limb and the masseter muscle contralateral to that limb. In the second monkey, we monitored trapezius, deltoid, triceps, biceps, flexor carpi radialis, flexor carpi-ulnaris, extensor carpi radialis, extensor carpi ulnaris, cervical paravertebral, latissimus dorsi, flexor carpi ulnaris, and one group each of thigh flexors and extensors on the right side of the body. The triceps, brachialis, and extensor carpi radialis muscles were studied on the left.

Data analysis. To evaluate the monkey's learning and performance, we measured the number of correct responses in a three-trial moving average. The probability, by chance alone, of choosing three consecutive correct responses is less than $2 \%\left(0.25^{3} \approx 0.016\right)$, and we took this performance level to indicate that significant learning had occurred. Rarely did either monkey's performance deteriorate once it reached that level, and the second of those three trials was designated as the time (or trial) of critcrion achicvement.

Examination of raster and histogram displays, aligned on the presentation of the instruction stimulus (IS) and the trigger signal (TS), allowed the initial classification of each PM neuron. Following Weinrich and Wise (1982; see also Mauritz and Wise, 1986), the following task periods served to define activity patterns in PM: the $500 \mathrm{msec}$ prior to IS presentation (anticipatory activity), a period less than $1 \mathrm{sec}$ after IS presentation (signal-related activity), the latter part of the instructed delay period (set-related activity), and the $200 \mathrm{msec}$ before the onset of movement to the target position (movement-related activity). Activity levels reported here represent mean discharge rates during the appropriate task period or a designated part of one.

Cells were not tested for learning dependency if they showed a sudden change in neuronal activity across all task periods. Anticipatory and signal-, set-, and movement-related activities were analyzed separately, each as a separate instance of task-related activity. Accordingly, a neruon could be tested for learning-dependent activity changes in up to four task periods. In practice, though, we found only one cell with learningdependent activity in more than two task periods. For each instance of learning dependency, we evaluated whether the activity being studied showed significant task-related modulation, defined as a significant difference from its activity during an appropriate reference period. The 500 -msec period just prior to the instruction stimulus usually served as the reference, except for the three cells showing anticipatory activity (Mauritz and Wise, 1986; Vaadia et al., 1988), in which cases we chose another period as the reference.

To identify neurons showing learning-dependent changes in activity, one trial, selected by visual inspection, served as the dividing line between early and late trials. Using data from the relevant task period, we compared all early trials, as a group, against all late trials (MannWhitney $U$ test at the $5 \%$ significance level). In the event of a statistically significant difference, the same test was performed on reference activity. If reference activity also showed a significant difference in the same early versus late trials, we excluded the cell on the grounds that some nonspecific alteration of cell excitability might have occurred.

For each instance of learning-dependent activity, we calculated a learning dependency index, $L . L=A_{n} /\left(A_{1}+A_{n}\right)$, where $A_{1}$ is the activity in the first correct trial and $A_{n}$ is the last-trial activity for a given novel stimulus. When neuronal activity did not change with learning, $L=$ 0.5 . Values near 1.0 indicate the largest proportional increases in activity during learning. Because $L$ expresses learning dependency in relative terms, we plotted $L$ against $A_{n}-A_{1}$, which shows the absolute activity change during learning (see Fig. 14). (For simplicity of illustration and analysis, we excluded cells with decreases in activity during learning from Fig. 14, as well as from the analysis shown in Fig. 3.)

Histology. Near the end of physiological data collection, we made electrolytic lesions (15 $\mu \mathrm{A}$ for $10 \mathrm{sec}$, anodal current) along four tracks in the first monkey and five tracks in the second. One week later, while perfusing the brain with formaldehyde, steel pins were inserted at known coordinates. The brain was removed, photographed, sectioned on a freezing microtome at $40 \mu \mathrm{m}$ thickness, mounted on glass slides, and stained for Nissl substance with thionin. We plotted the surface projections of the recording sites and the estimated track of each penetration by reference to the recovered electrolytic lesions and to the pin holes. All four lesions could be observed in the first monkey's histological material. In the second monkey, three of the five lesions were found. We made no attempt to identify each recording track in the histological material. Cytoarchtectonic boundaries were identified according to criteria discussed in detail elsewhere (Weinrich and Wise, 1982; Wisc, 1984, 1985b).

\section{Results \\ Behavior}

The first monkey reached a level of $95 \%$ correct responses to the four familiar stimuli in 50 training sessions. The second monkey took 53 sessions to achieve that level. Each animal then learned to respond to novel stimuli. We increased the number of novel stimuli from one novel stimulus to four in a set of four stimuli. Beforc the recording sessions began, the first monkey had seen 141 novel stimuli and solved over 127 of these "problems" to a level of $90 \%$ correct. The second monkey had solved 838 problems. The training involving novel stimuli took 43 and 106 sessions in the first and second monkey, respectively. Presentation of familiar stimuli continued during this period, and the monkeys' performance gradually improved for both novel and familiar stimuli. As the monkeys' performance improved further during the training and recording sessions, we increased the number of novel stimuli in a set from four to eight.

Once neuronal recording began, the monkeys rarely $(<1 \%$ of trials) emitted an incorrect response to familiar stimuli. A sample of task performance, from 12 early, middle, and late recording sessions, shows that the animals learned new stimulusresponse associations comparably for those stimuli instructing leftward, downward, and rightward responses. The first monkey learned correct leftward responses to the criterion level of performance (see Materials and Methods) in $9.4 \pm 7.8( \pm \mathrm{SD})$ trials (range, 2-28), downward responses in $11.0 \pm 5.3$ trials (range, $2-21$ ), and rightward responses in $9.2 \pm 7.5$ trials (range, 2-31). No-go responses were learned more quickly; the monkey averaged $2.5 \pm 1.2$ trials (range, $2-6$ ) to reach criterion. The second monkey learned correct leftward responses in $7.7 \pm 6.0$ trials (range, 2-19), downward responses in $10.3 \pm 6.5$ trials (range, 3-25), and rightward responses in 9.8 \pm 6.3 trials (range, 3-22). As with the first monkey, the second learned no-go responses more quickly, averaging $3.6 \pm 3.7$ trials (range, 2-14) trials. We could not discern any systematic strategy of response choice or any response bias, except that both monkeys often favored nogo responses (Table 1).

We used two measures for the monkeys' speed of reaction: initial response time (IRT) and EMG modulation time. IRT was defined as the time from the TS to the handle's interruption of the infrared beam along the path from the origin position to the final target. Thus, the IRT includes both reaction time (RT), as traditionally defined (the time from the TS until movement onset), and a substantial element of movement time (MT). The IRT typically averaged approximately $475 \mathrm{msec}$ for both monkeys. As for EMG modulation time, the earliest rise above background activity occurred from 225 to $260 \mathrm{msec}$ after stimulus presentation for all three movement directions in the first mon- 
Table 1. Samples of response selection following novel stimuli instructing downward, rightward, leftward, and no-go responses

\begin{tabular}{|c|c|c|c|c|c|c|c|c|c|c|c|c|c|c|c|}
\hline \multirow{2}{*}{$\begin{array}{l}\text { Correct } \\
\text { response }\end{array}$} & \multicolumn{15}{|c|}{ Trial number } \\
\hline & 1 & 2 & 3 & 4 & 5 & 6 & 7 & 8 & 9 & 10 & 11 & 12 & 13 & 14 & 15 \\
\hline \multirow[t]{6}{*}{ Down (D) } & $\mathbf{L}$ & + & + & + & \pm & + & + & & & & & & & & \\
\hline & $\mathbf{R}$ & L & $\mathrm{L}$ & + & $\mathbf{R}$ & + & + & + & + & + & + & + & + & + & \\
\hline & $\mathbf{R}$ & + & $\mathrm{R}$ & $\mathrm{L}$ & + & + & + & + & + & + & + & + & + & + & + \\
\hline & + & + & + & + & + & + & + & + & & & & & & & \\
\hline & $\mathbf{N}$ & $\mathbf{R}$ & + & + & $\mathbf{R}$ & + & + & + & & & & & & & \\
\hline & $\mathbf{N}$ & $\mathbf{L}$ & $\mathbf{N}$ & $\mathrm{R}$ & + & + & + & + & + & + & + & + & + & + & + \\
\hline \multirow[t]{5}{*}{ Right (R) } & $\mathrm{N}$ & $\mathbf{L}$ & $\mathbf{N}$ & $\mathrm{D}$ & $\mathbf{L}$ & + & + & + & & & & & & & \\
\hline & $\mathrm{N}$ & + & + & + & + & & & & & & & & & & \\
\hline & $\mathbf{N}$ & $\mathbf{N}$ & $\mathbf{N}$ & $\mathbf{L}$ & + & $\mathrm{N}$ & $\mathrm{N}$ & $\mathrm{N}$ & + & + & + & & & & \\
\hline & $\mathrm{N}$ & $\mathrm{N}$ & $\mathbf{N}$ & $\mathbf{N}$ & $\mathrm{N}$ & + & + & + & + & & & & & & \\
\hline & $\mathbf{N}$ & $\mathrm{N}$ & L & + & + & $\mathrm{N}$ & + & + & + & & & & & & \\
\hline \multirow[t]{6}{*}{ Left (L) } & $\mathbf{R}$ & $\mathrm{D}$ & + & $\mathbf{N}$ & + & + & + & + & + & + & + & + & + & + & + \\
\hline & $t$ & 1 & 1 & $t$ & 1 & + & + & + & + & + & + & + & + & + & \\
\hline & $\mathrm{N}$ & D & + & + & + & + & + & + & + & + & + & + & + & + & + \\
\hline & $\mathrm{N}$ & D & + & + & + & + & + & + & + & + & + & + & + & + & + \\
\hline & $\mathrm{N}$ & $\mathrm{N}$ & D & $\mathbf{R}$ & + & + & + & + & + & + & + & + & & & \\
\hline & $\mathrm{N}$ & $\mathbf{R}$ & D & + & $\mathbf{R}$ & D & + & $\mathbf{R}$ & + & $\mathbf{R}$ & + & + & + & & \\
\hline \multirow[t]{6}{*}{ No-go (N) } & $\mathbf{R}$ & + & + & + & + & + & + & + & + & + & + & + & + & + & + \\
\hline & + & + & + & + & + & + & + & + & + & + & + & + & + & + & + \\
\hline & + & + & + & + & + & + & + & + & + & + & + & + & + & + & + \\
\hline & $\mathbf{L}$ & $\mathbf{L}$ & $\mathbf{R}$ & D & L & + & $\mathrm{L}$ & + & + & + & + & + & + & + & + \\
\hline & + & + & + & + & + & + & + & + & + & + & + & + & + & + & + \\
\hline & D & $\mathbf{R}$ & $\mathrm{D}$ & + & D & $\mathbf{L}$ & $\mathbf{R}$ & + & $\mathrm{L}$ & D & $\mathrm{R}$ & $\mathrm{D}$ & + & + & + \\
\hline
\end{tabular}

Correct responses are indicated with a plus sign (+). Each row shows responses to a different novel stimulus, and only the first 15 responses are shown.

key. In the second monkey, it occurred a little faster, from 200 to $250 \mathrm{msec}$ before the TS for both novel and familiar stimuli.

In order to study the time course of any consistent changes in response time during acquisition of stimulus-response associations, we averaged the IRTs from 6-10 representative samples ranging from the first to the last recording week (Fig. 2), aligning each sequence of response times on the trial in which the monkey first achieved criterion performance (normalized trial 0; see Materials and Methods). Averaged over the sample of responses in a given direction, the mean IRT did not vary systematically with date of recording or between familiar and novel stimuli. There was no significant time trend for novel stimuli for either monkey ( $p>0.08$, one-factor ANOVA with repeated measures). However, visual inspection suggested that the first monkey did respond more quickly, with time, when the novel stimulus instructed a rightward movement, and a $t$ test confirmed that trials -2 and 2 differed significantly $(p<0.05)$ for that direction in the first monkey (Fig. 2, upper right). Thus, the tendency for the monkey to respond more quickly as a stimulus-response association strengthened was inconsistent and

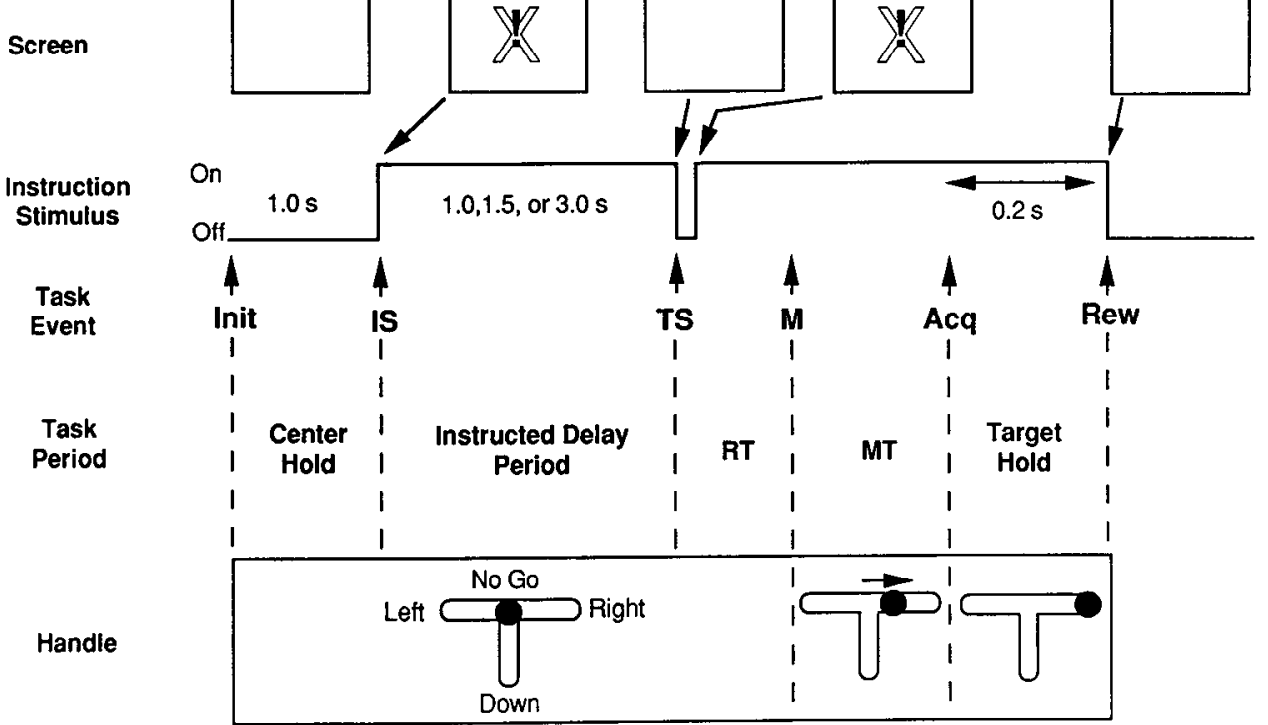

Figure 1. Schematic of video screen and task sequence. Top row, Video screen during various task periods. Second row, Trace indicating when the IS is on. Third and fourth rows, Names of task events and task periods, respectively. Bottom row, Facsimile of the handle, the names of the four possible responses, and, for a rightward movement, the state of the handle during different task periods. Time dimension is not to scale. Init, trial initiation; IS, instruction stimulus; $T S$, trigger stimulus; $M$, movement; $A c q$, target acquisition; Rew, reward. 

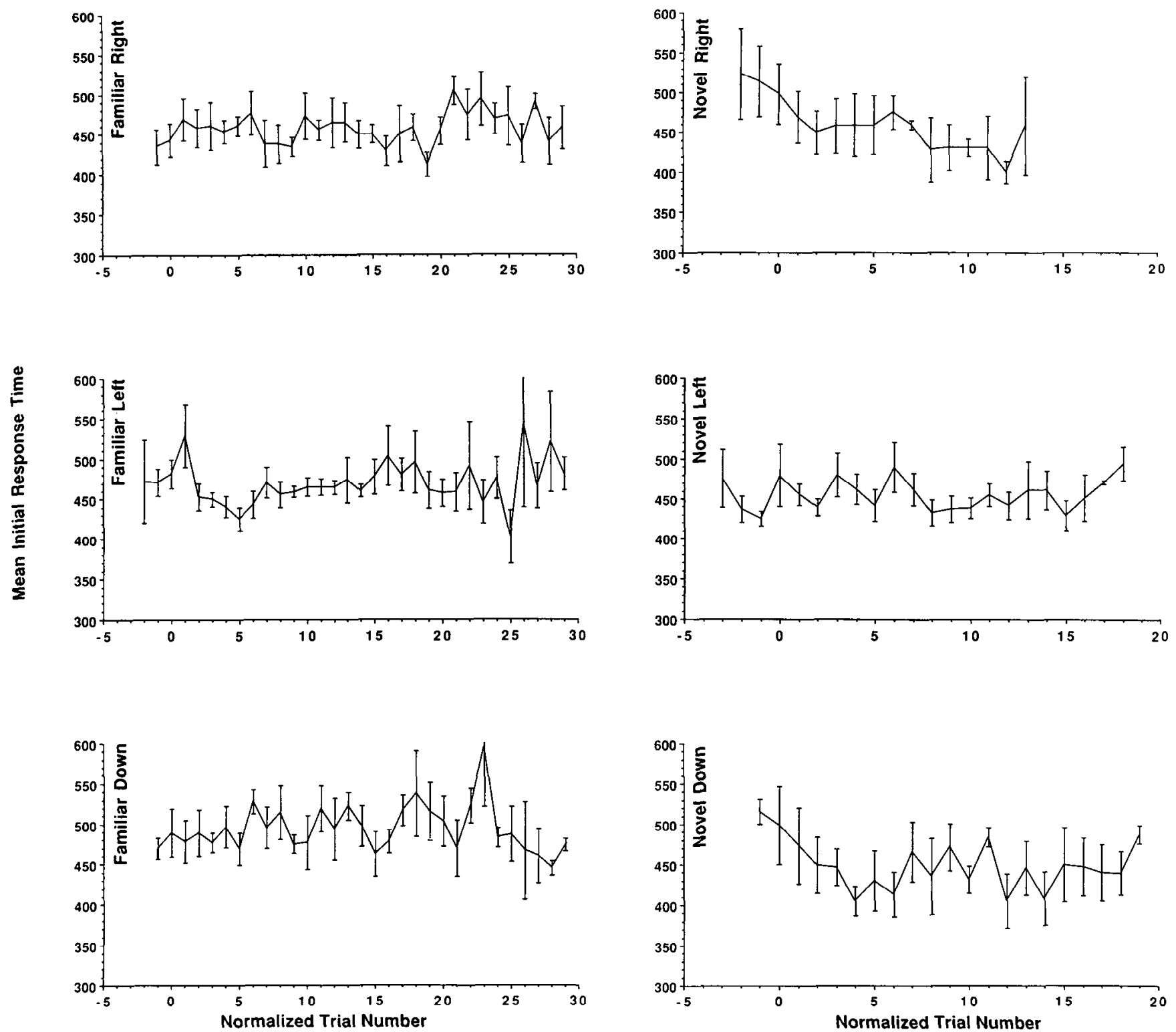

Figure 2. Mean IRTs for the first monkey. Left column, Responses following familiar instruction stimuli for cach direction of movement. Right column, Response times after novel stimuli. Normalized trial 0 represents the middle of three consecutive trials in which the monkey achieves criterion performance (three consecutive correct responses) for a given stimulus and is the same as trial 0 in Figures 3 and 4 (see Materials and Methods). Error bars indicate the SEM.

rarely statistically significant in the general sample of each monkey's behavior. Among familiar stimuli, only responses to the left in the first monkey showed a significant time trend $[F(8)=$ 3.00, one-factor ANOVA with repeated measures]. Post hoc tests showed that this effect could be attributed to the normalized trial 1 [Fischer protected least significant difference test (PLSD), $p<0.05]$.

We separately analyzed the IRTs for trials corresponding to the population activity and performance data presented in Figure 3 (Fig. 4). Thus, for each instance of learning-dependent increases in cell activity, from which our neuronal population averages were calculated, we examined the monkeys' IRT as a function of normalized trial number. Trial 0 represents the trial in which the monkey first achieved criterion performance (see
Materials and Methods). Inspection of the IRTs for each instance of learning-dependent activity change reveals that in several instances the IRT decreased as the monkey learned. However, in many other instances the IRT did not change or it even increased as learning progressed. Thus, there was no obligatory link between increasing activity during learning novel conditional motor associations and decreasing IRT. Figure 4 shows the IRT for each monkey, averaged across all movement directions. There was no significant time trend for the first monkey $(p>0.5)$, but the second monkey showed significantly faster IRT with increasing trial number $[F(13)=2.84 ; p<0.002$; one-factor ANOVA with repeated measures]. Post hoc tests (Fischer PLSD test, $p<0.05$ ) identified normalized trials -2 and -1 as significantly different from most or all other trials 

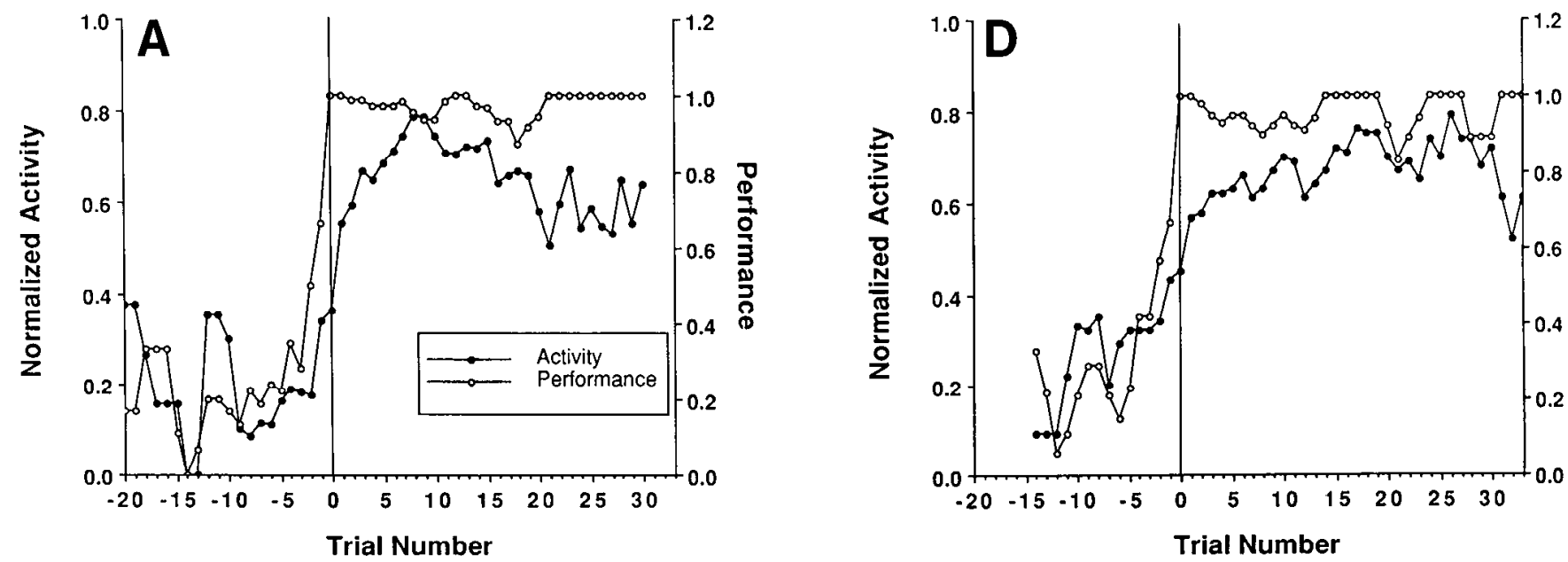


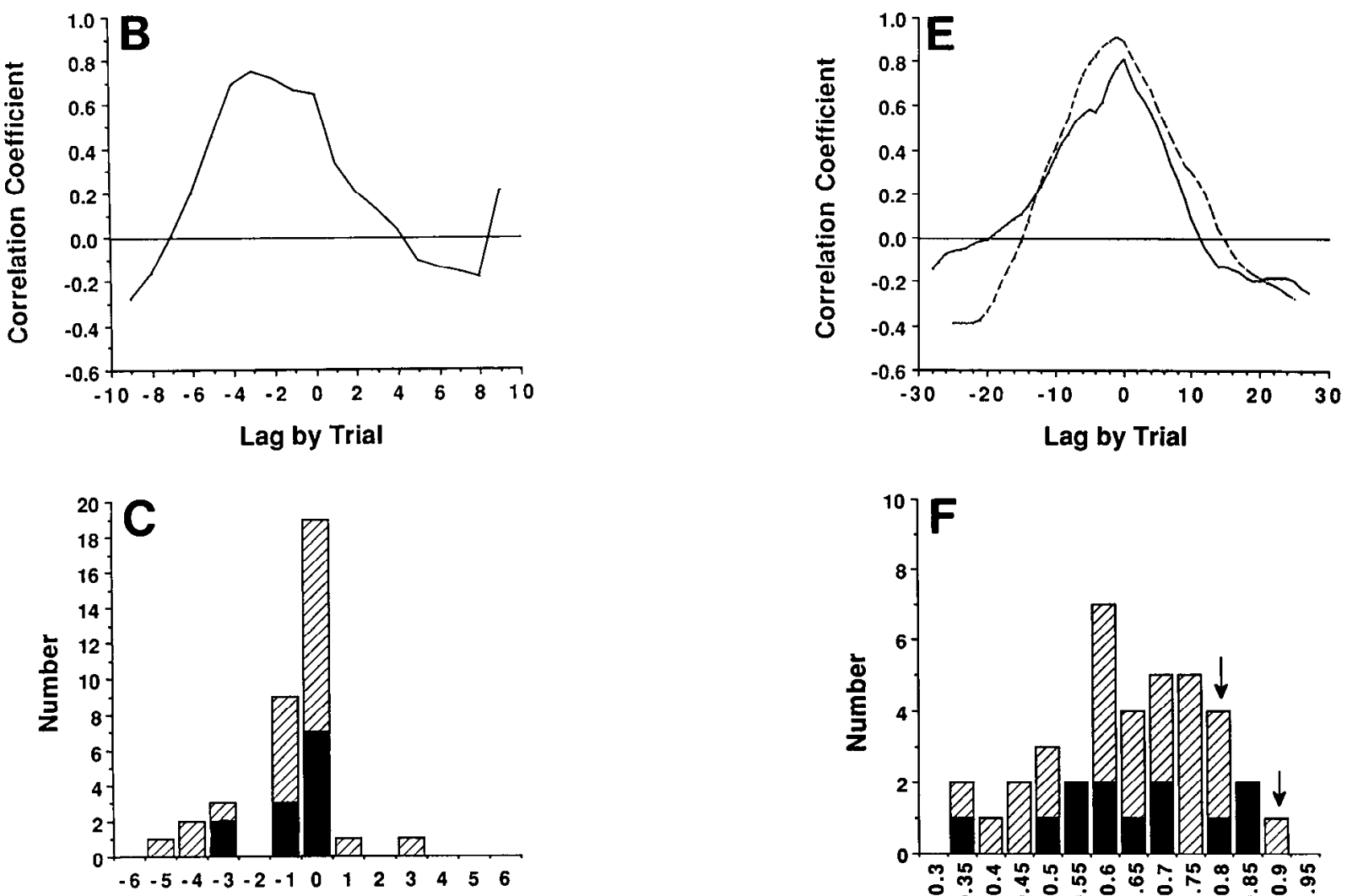

Lag by Trial

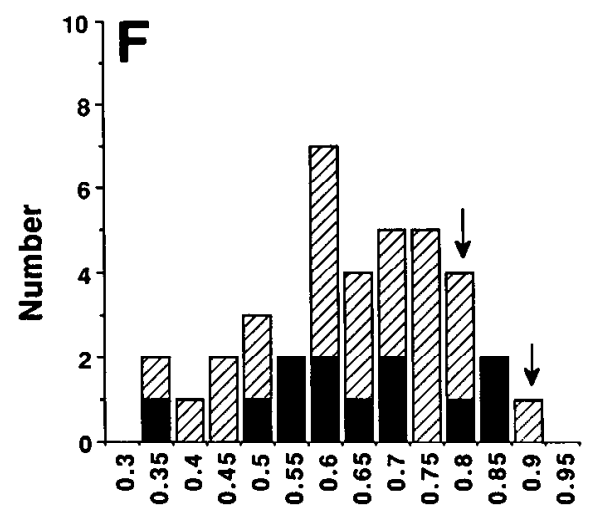

Correlation Coefficient

Figure 3. Population data. $A$ and $D$ show, for the first $(n=29)$ and second $(n=14)$ monkey, respectively, population averages of improvements in performance (open circles) and increases in task-related activity (solid circles). The population averages combine instances of signal-, set-, and movement-related activity, but exclude cells with activity decreases during learning. Each curve is aligned on achievement of criterion performance (the second of three consecutive correct responses, which is defined as trial 0 ). Both performance and activity curves are from three-point, centered moving averages. Activity data were normalized to the maximal three-point average for each instance, then averaged. $B$ and $E$, Cross correlations of activity curves with performance curves. Negative lags indicate that the improvement in performance leads activity; positive lags indicate that the improvement in performance lags activity. $B$ is from a single instance of learning-dependent activity: the data illustrated in Figure $6 A$. Its peak correlation was $r=0.75$ at a lag of -3 trials. $E$ shows the cross correlations for the population means from the first (broken line) and second (solid line) monkey. $C$ and $F$, Frequency distributions (hatched bars for the first monkey, solid bars for the second) for each instance of learning-dependent increase. $C$ shows the distribution of lags for the peak correlation. $F$ shows the distribution of peak correlation coefficients for the data included in $A$ and $D$. Arrows indicate the peak correlation coefficient of the two population means: $r=0.91$ for the first monkey; $r=0.81$ for the second. 


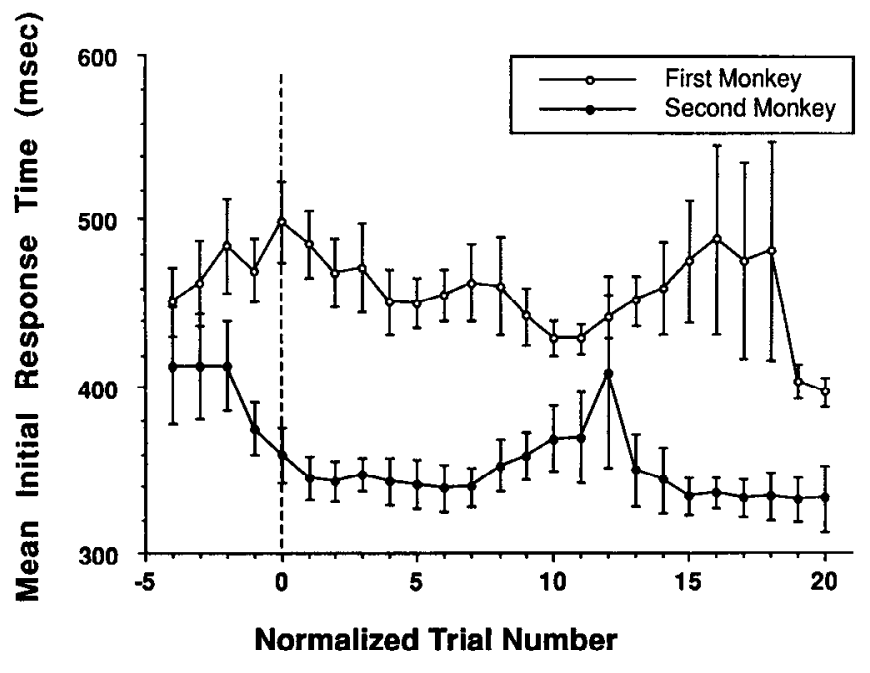

Figure 4. Mean IRTs for each instance of learning-dependent increase in activity, the data used to construct the population averages shown in Figure 3. Normalized trial 0 is the same as in Figure 2. All directions of movement are combined for each monkey. This sample of behavior is different from the general sample illustrated in Figure 2. Error bars indicate SEM.

up to and including trial 10 . Thus, very close to the time (trial 0 ) when the monkey achieved criterion performance, IRT had stabilized.

\section{Electromyography}

The muscles of the upper right half of the trunk and the right limb (deltoid, wrist flexors, biceps, triceps, trapezius, cervical paravertebral, pectoralis major, infraspinatus, sternocleidomastoid) showed the most task-related activity in the first monkey. For nearly all muscles, activity diminished during the period immediately before the IS. This diminution in activity continued throughout the delay and reward periods for stimuli instructing the monkey not to move the handle. In right-side wrist extensors, EMG activity increased just prior to leftward, downward, and rightward movements. The same was true for wrist flexors, except for rightward movements, in which activity began building up in the delay period. Delay-period activity was constant, except for the following: as noted above in wrist flexors, phasically in the right biceps prior to rightward and downward handle movements, and weakly in the right cervical paravertebral muscles prior to rightward movements. All EMG records were examined to determine if there were significant changes in activity during learning the new conditional motor associations. Four muscles (infraspinatus, wrist extensors, triceps, and trapezius) showed much weaker task-related activity after the monkey learned the instructional significance of a stimulus. In no muscle did we observe activity patterns that paralleled the learning-dependent increases in cortical activity.

In the second monkey, certain muscles in the right forelimb appeared to make consistent contributions to leftward (triceps, flexor carpi ulnaris, brachioradialis) or rightward (triceps, deltoid, extensor carpi ulnaris) movement, whereas a greater number contributed to downward movements (triceps, deltoid, biceps, flexor carpi radialis, flexor carpi ulnaris, brachioradialis, extensor carpi radialis, extensor carpi ulnaris). Unlike the other animal, this monkey made brief forelimb contractions following the IS. In one case, right biceps, the contractions depended upon

\begin{tabular}{|c|c|c|c|c|}
\hline \multirow[b]{2}{*}{ Activity pattern } & \multicolumn{2}{|l|}{ PM } & \multicolumn{2}{|l|}{ M1 } \\
\hline & Tested & Positive $^{a}$ & Tested & Positive $^{\alpha}$ \\
\hline \multicolumn{5}{|l|}{ First monkey } \\
\hline $\begin{array}{l}\text { Anticipatory } \\
\text { Signal related } \\
\text { Set related } \\
\text { Movement related } \\
\text { Total instances } \\
\text { Total cells }\end{array}$ & $\begin{array}{l}2 \\
19 \\
14 \\
15 \\
50 \\
33\end{array}$ & $\begin{array}{l}2 \\
15 \\
10 \\
10 \\
37 \\
30\end{array}$ & $\begin{array}{l}0 \\
0 \\
0 \\
2 \\
2 \\
2\end{array}$ & $\begin{array}{l}0 \\
0 \\
0 \\
2 \\
2 \\
2\end{array}$ \\
\hline \multicolumn{5}{|l|}{ Second monkey } \\
\hline $\begin{array}{l}\text { Anticipatory } \\
\text { Signal related } \\
\text { Set related } \\
\text { Movement related } \\
\text { Other } \\
\text { Total instances } \\
\text { Total cells }\end{array}$ & $\begin{array}{l}1 \\
5 \\
11 \\
6 \\
1 \\
24 \\
20\end{array}$ & $\begin{array}{l}0 \\
5 \\
6 \\
2 \\
0 \\
13 \\
10\end{array}$ & $\begin{array}{l}1 \\
3 \\
5 \\
10 \\
0 \\
19 \\
14\end{array}$ & $\begin{array}{l}1 \\
2 \\
3 \\
2 \\
0 \\
8 \\
7\end{array}$ \\
\hline $\begin{array}{l}\text { Total instances } \\
\text { Total number of cells }\end{array}$ & $\begin{array}{l}74 \\
53\end{array}$ & $\begin{array}{l}50 \\
40\end{array}$ & $\begin{array}{l}21 \\
16\end{array}$ & $\begin{array}{l}10 \\
9\end{array}$ \\
\hline
\end{tabular}

the instructed direction, whereas in eight other cases (right paravertebral, flexor carpi radialis, flexor carpi ulnaris, thigh flexors, latissimus dorsi, deltoid, extensor carpi ulnaris, left brachialis) they were nondirectional or inconsistent. The biceps EMG increased phasically both before downward movement and after a stimulus that instructed a rightward movement. Its magnitude increased as the monkey learned conditional associations. Aside from this case, the pattern of EMG activity did not closely resemble the learning-dependent increases in neuronal activity.

\section{Neuronal activity}

The present analysis concentrated on a comparison of neuronal activity during correctly performed trials segregated into two groups: (1) the first few correct trials, when the monkeys' overall rate of success was generally low and (2) later trials in which the monkeys generally made few, if any, wrong responses. Table 2 shows the number of instances of learning-dependent activity from each monkey and the number of instances with sufficient data for adequate testing. In the first monkey, 30 of the $37(81 \%)$ learning-dependent activity changes were increases; seven were decreases. In the second monkey, 14 of the $21(67 \%)$ learningdependent changes were increases. Aside from the sign of their activity change, the properties of cells with activity decrcascs closely resembled those with increases. The analysis presented below concentrates on cells with increasing activity during conditional motor learning.

Cells in the PM showed the diversity of task-related activity patterns commonly reported in the past (Weinrich and Wise, 1982; Mauritz and Wise, 1986). Anticipatory and signal-, set-, and movement-related activity patterns were observed in the present sample. In most instances, the pattern of task-related discharge changed little as the activity level evolved during visuomotor learning. For example, cells that showed increased setrelated activity with learning did not change from signal- or movement-related to set-related activity. By definition, cells designated as learning dependent could not significantly change activity during the reference period (see Materials and Methods). However, other cells (nine in the first monkey, 13 in the second) 


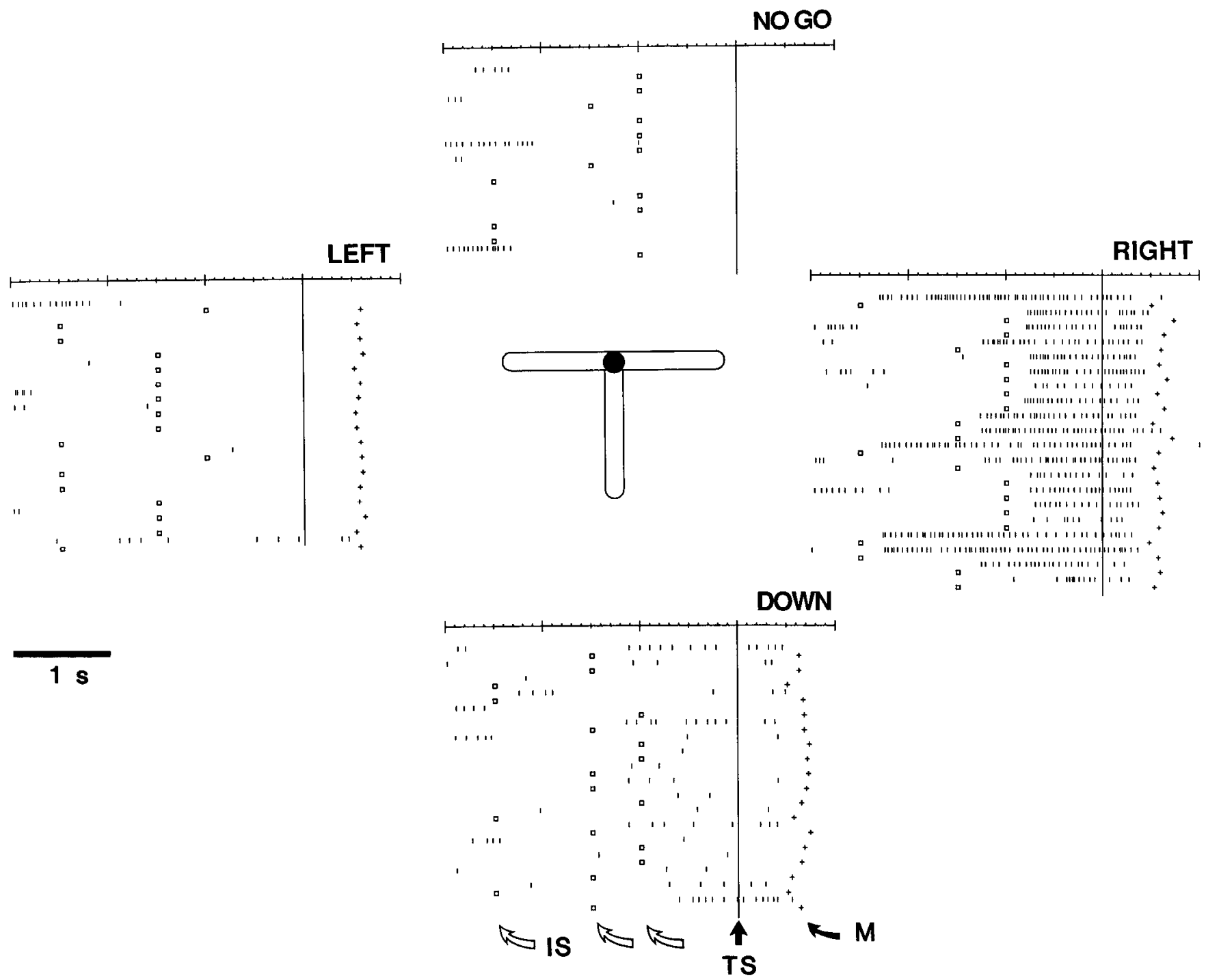

Figure 5. A set-related PM neuron during the presentation of familiar stimuli. Each raster line shows neuronal discharge during one trial. Beneath each raster line, an open square indicates when the $I S$ (open arrows) appeared on that trial, and a plus sign (+) indicates when movement ( $M$ ) began. The solid vertical line indicates the time of the TS, on which each raster is aligned. A facsimile of the handle appears in the center of the figure. Note that the cell discharges most vigorously after an instruction that the upcoming movement will be to the right. Time scale: major divisions, $1 \mathrm{sec}$; minor divisions, $100 \mathrm{msec}$.

did change their overall discharge rate with increasing stimulus familiarity. We excluded these cells from further analysis because of the possibility that their activity reflected a generalized alteration of neuronal excitability.

Figures 5-7 illustrate a representative learning-dependent activity change and the cell's activity after familiar stimuli. This set-related neuron was selective for rightward responses when the familiar stimuli guided response selection (Fig. 5). After a novel stimulus instructed the same rightward response, the cell showed little modulation preceding the first few correct responses, but steadily increased its firing as the animal executed additional correct responses (Fig. 6A). Note that Figure $6 \mathrm{~A}$ illustrates only trials in which correct responses were made; trials with incorrect responses have been eliminated. Thus, despite the fact that in each correct trial the same response followed an identical stimulus, early correct trials were associated with little or no activity, whereas later trials showed signiticant set-related activity. This observation was repeated for several different nov- el stimuli, each of which, the monkey eventually learned, instructed a rightward response (Figs. 6, 7).

Five key features of learning-dependent activity increases appeared consistently:

(1) The increase in cell activity closely paralleled the improvement in task performance (Figs. $3 A, D ; 7$ ), but in many instances, activity changes appeared to lag behind the learning curve (Fig. $3 C$ ). To reach $80 \%$ of their peak activity level, cells from the first monkey $(n=26)$ took $7.0 \pm 5.3$ correct trials after the first achievement of criterion performance (three consecutive correct) and $6.3 \pm 5.2$ correct trials after the final achievement of criterion. [The difference results from the rare instances $(n=3)$ in which the monkey's performance deteriorated after first achievement of criterion performance.] The analogous numbers for the second monkey $(n=12)$ were $6.2 \pm 4.4$ and $4.9 \pm 3.6$ correct trials, respectively. Correlations between cell activity changes and improved performance were large and highly significant (Fig. $3 F$ ). Note the arrows in Figure $3 F$, which 


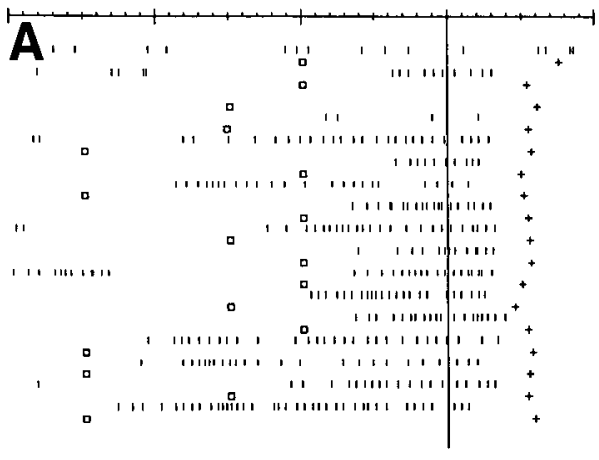

Figure 6. Evolution of set-related activity during conditional motor learning: same cell as in Figure 5. $A-C$, Activity during the presentation of three different novel stimuli $(I S)$, each instructing movements to the right $(R)$. Raster format is the same as in Figure 5. Time scale: major divisions, $1 \mathrm{sec}$ minor divisions, $100 \mathrm{msec} . D-F$, Each trial-by-trial plot of set-related activity corresponds to the raster at its left, as measured in the final $650 \mathrm{msec}$ before the TS. (Because activity is presented for correctly executed trials only, some trials lack activity points.) The broken horizontal lines indicate \pm 1 SD of the mean set-related discharge following the familiar stimulus instructing a rightward movement (see Fig. 5). Solid squares on the $\mathrm{x}$-axis mark the trials in which the monkey made erroneous responses, thus showing correct versus incorrect responses on a trial-by-trial basis. Note that the first correctly executed trials are associated with little or no setrelated activity, though stimulus and response are the same as in later trials. This cell was located at the site of the lesion in Figure $16 D$.
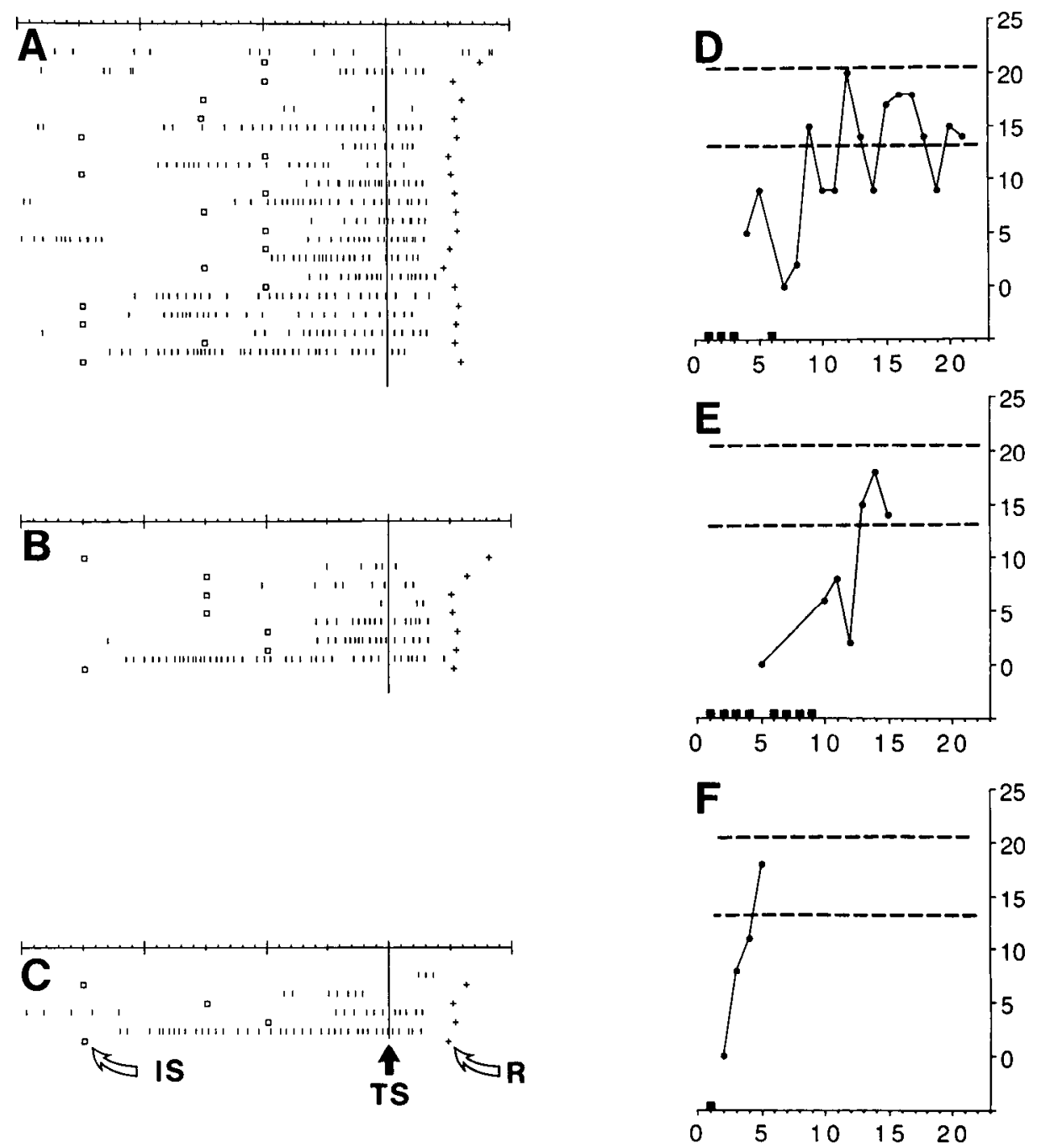

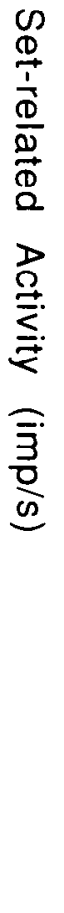

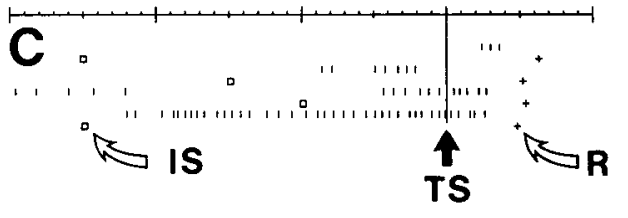

Trial Number show the correlation between population activity and performance curves for each monkey (Fig. $3 A, D$ ). Indeed, on those relatively rare occasions when performance fluctuated after first criterion achievement, the three-point activity and performance averages of individual neurons often covaried closely. More generally, when the monkey learned a given stimulus-response association rapidly, activity changed quickly; when the monkey learned more slowly, cells took longer to achieve their eventual level of activity (Figs. 6, 7). Activity associated with leftward, downward, and rightward movements showed similar rates of evolution, as did set-, signal-, and movement-related activity changes. (Few cells showed modulation during no-go trials, and the population of cells with anticipatory activity was too small for comparison with the other activity patterns.)

(2) Activity for correct responses usually exceeded that for incorrect responses in the same direction (Fig. 8). For set-related activity, $63 \%(n=16)$ of the instances of learning-dependent activity changes differed significantly (Mann-Whitney $U$ test, $p$ $<0.05$ ) for correct versus incorrect responses in a given direction. For movement-related activity, that value was $36 \%(n=$ $11)$, and for signal-related activity it was $64 \%(n=11)$. For several neurons, the monkey did not make an adequate number of wrong responses in a given direction for testing.

(3) Even for correct responses to a given stimulus, activity during periods of good performance exceeded that during poor performance (Fig. 9). This observation indicates that merely the passage of time or a number of trials was not sufficient to cause a change in activity level.

(4) When it was possible to present multiple sets of novel stimuli while recording from the same neuron, which we did for 14 learning-dependent cells in the first monkey and nine in the second, similar learning-dependent changes in activity occurred regardless of which stimulus instructed a given response (Figs. 6, 7). In the second monkey, all nine multiple-tested cells were studied with two novel stimuli for each response. In the first monkey, we studied six cells with two novel stimuli, three cells with three novel stimuli, and one cell each with four to eight novel stimuli for each response. Thus, the precise visual stimuli presented appeared to be unimportant for the learningdependent activity change.

(5) The activity following familiar stimuli of a given instructional significance was significantly, though by no means per- 

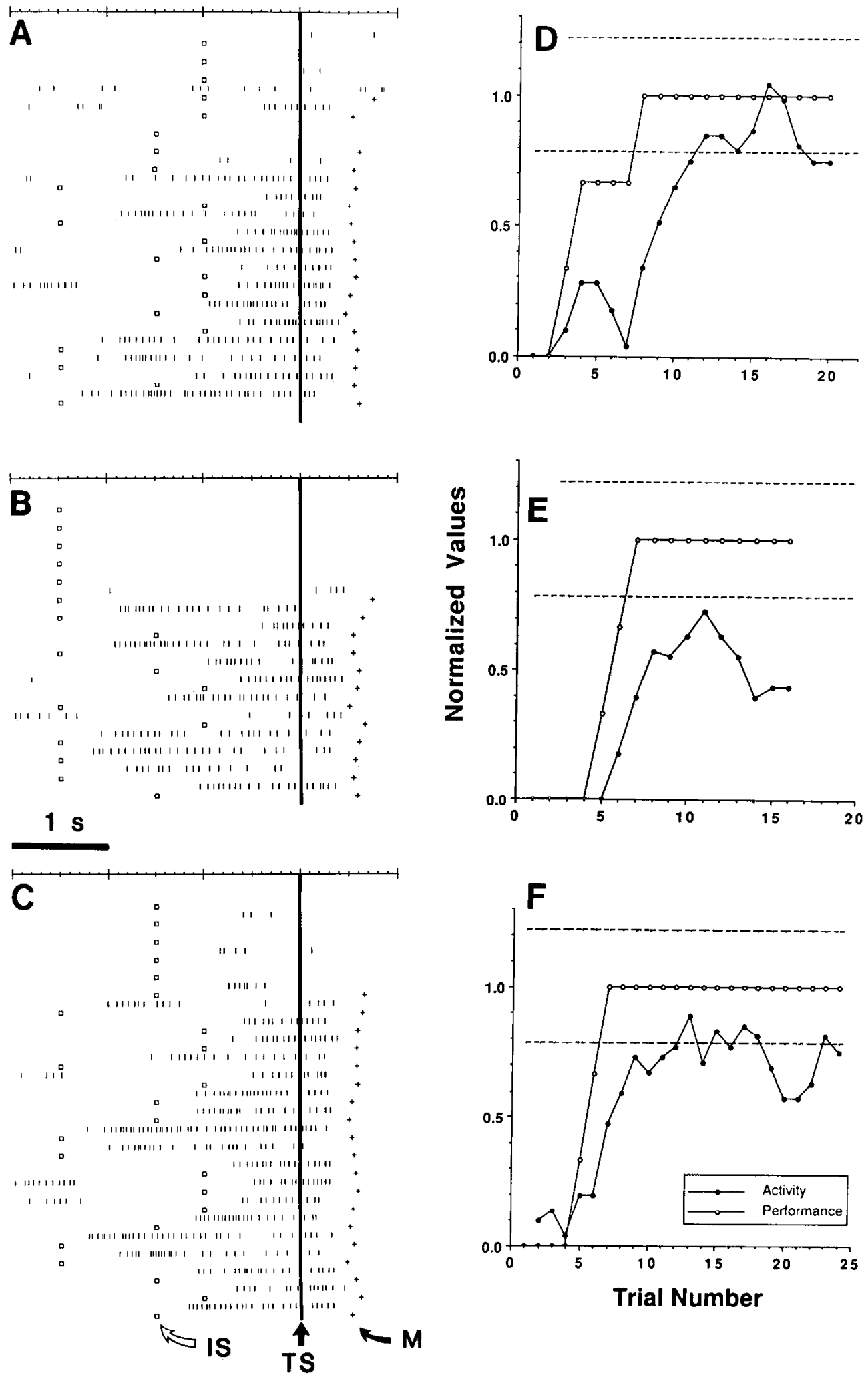

Figure 7. Activity during both correctly and incorrectly executed trials: same cell as in Figures 5 and $6 . A$ shows data for the same novel stimulus as Figure $6 A . A-C$, Each raster shows activity for a different novel stimulus, all instructing a rightward movement. Raster format is the same as in Figure 5. The plus sign $(+)$ beneath a trial's activity record indicates correctly executed trials, in which the monkey moved the handle to the right. On other trials, the monkey chose a different (and therefore incorrect) response. Table 1 gives examples of such choices. $D-F$, Behavioral (open circles) and cell-activity (solid circles) plots corresponding to the rasters to the left. Both curves are three-point, centered moving averages. The activity curve is normalized: each three-point average is divided by the maximal three-point average for that stimulus. The broken horizontal lines indicate $\pm 1 \mathrm{SD}$ of the mean set-related activity, familiar stimulus, rightward response (Fig. 5).

fectly, correlated with that ultimately developing for novel stimuli instructing the same response (Fig. 5, right, vs. Figs. 6, 7; Table 3).

Learning-dependent changes in activity occurred in all task periods (Table 2). Figures 10-13 document learning-dependent changes for set-related (Fig. 10), movement-related (Fig. 11), signal-related (Fig. 12), and anticipatory activity (Fig. 13). Learning-dependent changes in activity were observed in both the $46 \%$ of cells showing and the $54 \%$ lacking directional selectivity. For PM, $68 \%$ of the instances tested showed learningdependent changes in activity, $74 \%$ for the first monkey and $54 \%$ for the second. In M1, that percentage was $48 \%$, with all 

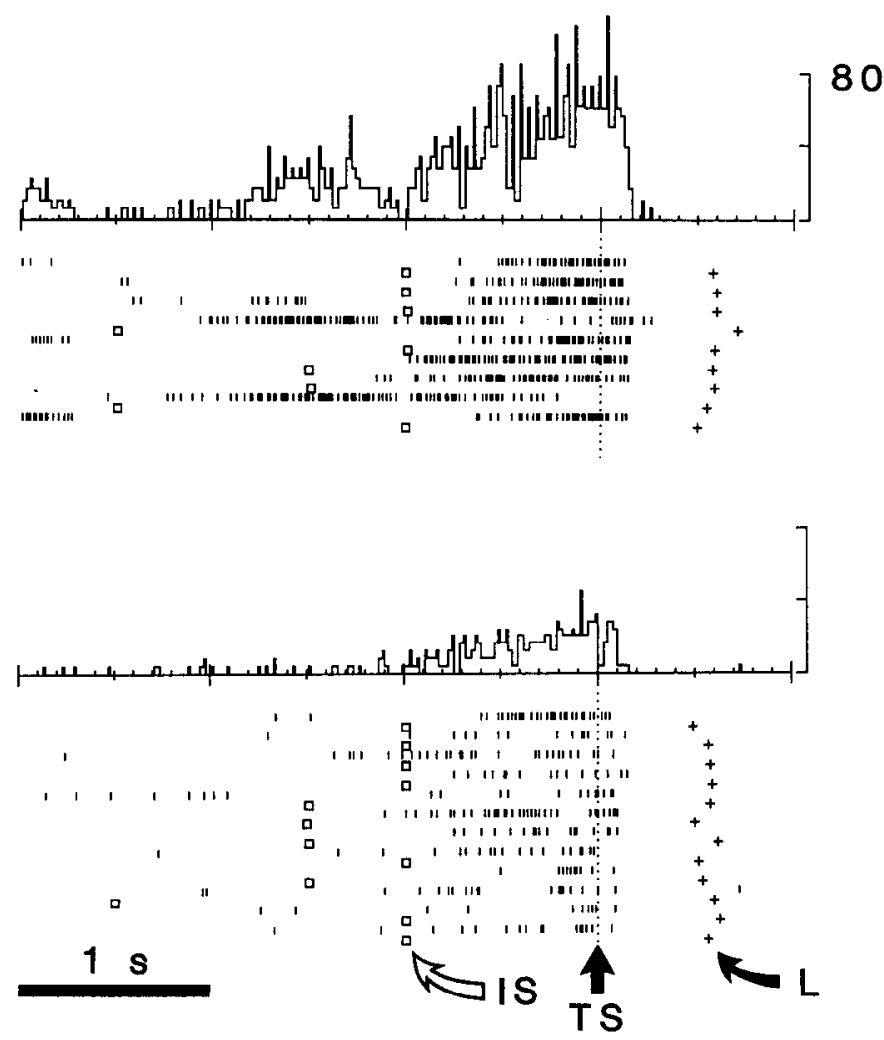

except two instances coming from the second monkey. Robust changes in learning-dependent activity occurred for all four activity patterns (Fig. 14; Table 3).

\section{Cortical localization and histological analysis}

Figures 15 and 16 show the locations of learning-dependent cells from the first monkey. Note, in particular, that whereas some penetrations have entered the cortex rostral to the arcuate sulcus, the learning-dependent neurons in these tracks were, according to our reconstruction, located near the fundus of the arcuate sulcus (Fig. 16D,E). Figure 17, $A$ and $B$, respectively, shows the cytoarchitecture and electrolytic marking lesions at coronal levels $J$ and $F$ in Figures 15 and 16. Figure 17A corresponds to the questionable area denoted on Figure 15J; Figure $17 B$ shows the characteristically amorphous cytoarchitecture of

Figure 8. Correct versus incorrect responses: activity of a PM cell, located at the site of the lesion in Figure 16E. Raster and histogram displays (bin width, $20 \mathrm{msec}$ ) are for trials with correct (top) and incorrect (bottom) leftward $(L)$ responses. Set-related activity before correct, leftward responses averaged $31.6 \pm 16.4$ impulses/sec. Significantly lower activity occurred when the same leftward movement is executed incorrectly, that is, following a novel stimulus that instructs a different response (mean $\pm \mathrm{SD}, 10.3 \pm 14.6 \mathrm{impulses} / \mathrm{sec}$ ). Note that, in contrast to the other displays, in the bottom raster the plus sign denotes incorrect movements. Activity scale, in impulses/sec, is identical for both histograms. Raster format is the same as in Figure 5.

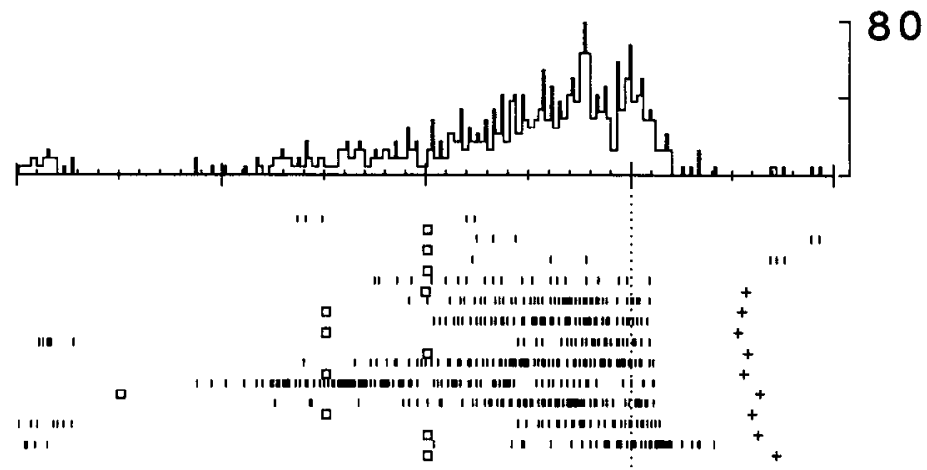

Figure 9. Rapid and consistent learning versus poor task performance: same PM cell as in Fig. 8; same format as in Fig. 7 , with the plus signs indicating trials with correct, leftward $(L)$ responses. Note the learning-dependent increase in set-related discharge when the monkey learns the stimulus-response association rapidly (top) and the lack of such change when performance is relatively poor (bottom), near the end of a recording session. Different stimuli were presented for the top and bottom displays. Activity scale, in impulses/sec, is identical for both histograms.

\section{$1 \mathrm{~s}$}

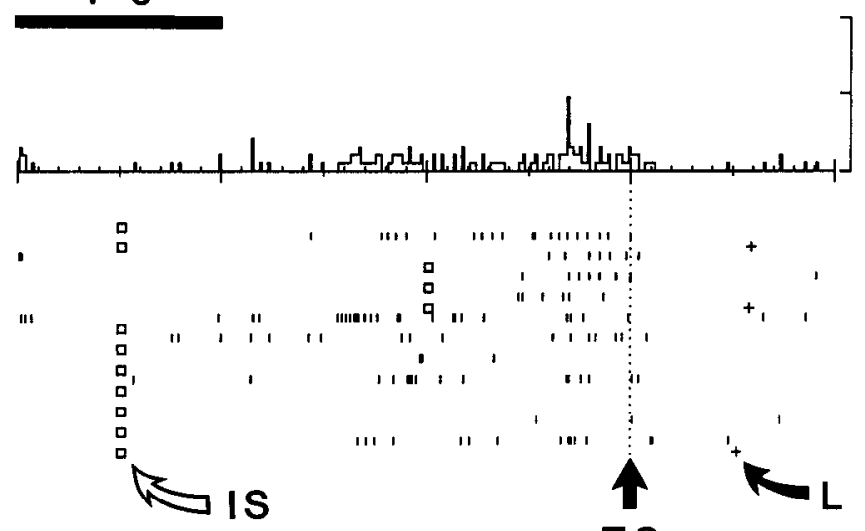



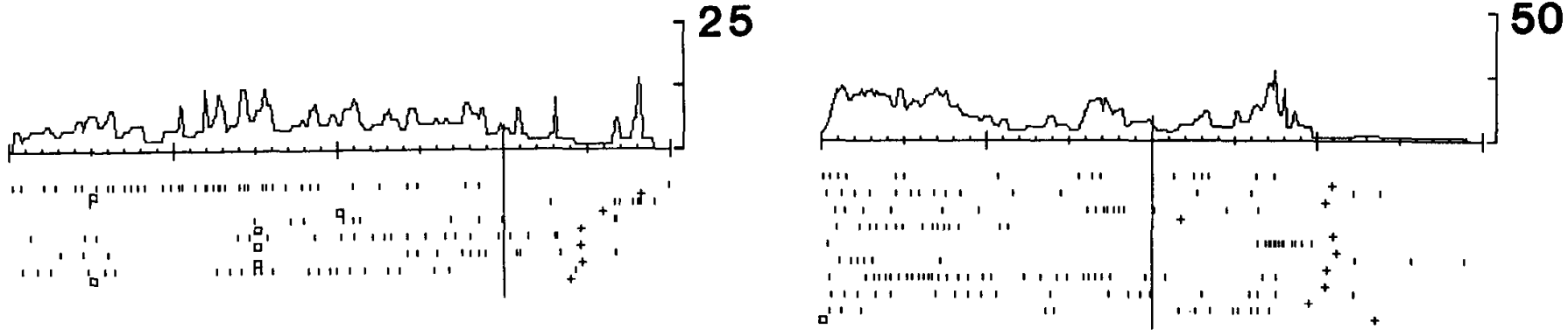

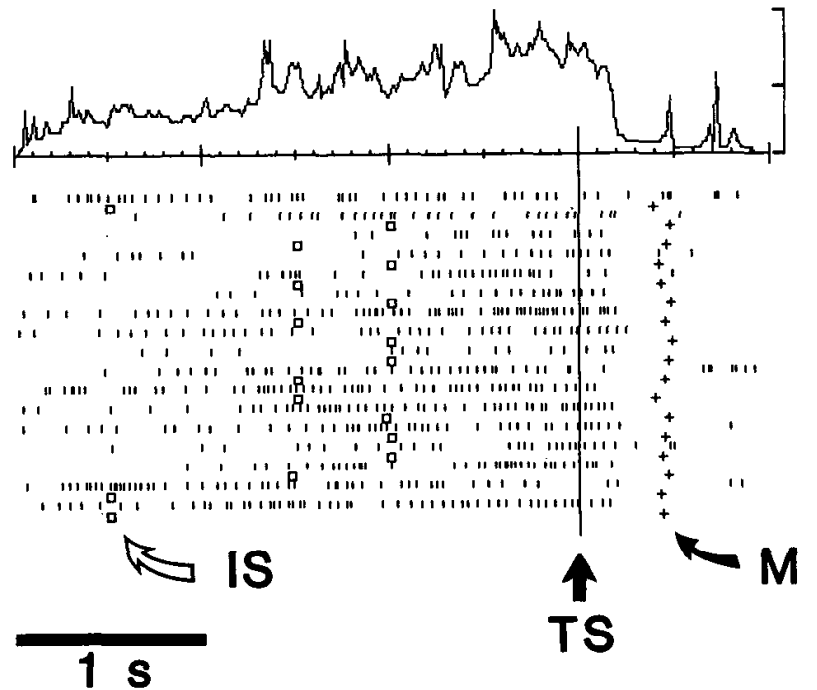

Figure 10. Set-related PM cell with learning-dependent activity changes from the second monkey: format as in Fig. 6; only trials with correct responses are displayed. Top, First six correct trials for a novel stimulus and the average activity as indicated by the reciprocal interval plot (RIP) above the raster display. Bottom, Final 17 correctly performed trials for the same stimulus. Activity scale, in impulses/sec, is identical for both RIPs. $M$, movement.

area 6 . Figure 18 shows the location of penetrations with learning-dependent changes in activity in the second monkey.

\section{Discussion}

Cells in PM change their activity during the acquisition of visuomotor conditional associations. This finding supports the hypothesis that PM plays a role in the selection of behavior on the basis of stimulus context (Passingham, 1988) and is consistent with a number of behavioral studies showing that such behavior does not survive damage to the PM (and adjacent) cortex (Halsband and Passingham, 1982, 1985; Petrides, 1982, 1986, 1987; Passingham, 1988; see also Crowne et al., 1989; Halsband and Freund, 1990). Learning-dependent cells may play a role in the retrieval of movements from memory (Passingham, 1988), including the association of responses with exteroceptive stimuli (Petrides, 1986).

The lag between improved performance and the evolution of neuronal activity, however modest and inconsistent from cell to cell, suggests that a sensorimotor association must already be established for activity in PM to approach its maximum level. On the assumption that cells involved in learning a stimulusresponse association would be most active early in the learning process, these data suggest that at least some PM cells function more in the retrieval process than in learning per se. Alterna-

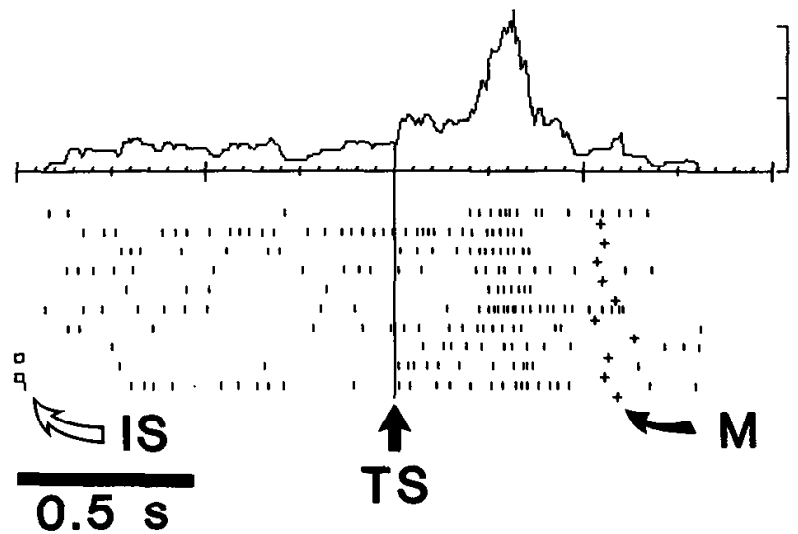

Figure 11. Movement-related PM ncuron from the first monkey. Displays are aligned on the $T S$, and only trials with correct responses are shown. Top. The first nine correctly performed trials show little or no movement-related activity, except for the fifth trial. Bottom. The last 10 correct responses have pronounced movement-related modulation. Activity scale, in impulses/sec, is identical for both RIPs.

tively, the activity lag, where observed, may simply reflect continued consolidation of the learned conditional association.

The present results can also be interpreted in terms of response preparation. The hypothesis that set-related activity in PM plays a role in some aspect of motor preparation has been repeatedly tested and supported (e.g., Weinrich and Wise, 1982; Weinrich et al., 1984; Wise and Mauritz, 1985; Kurata and Wise, 1988a,b). The general increase in activity during the learning of new conditional motor associations could reflect a more earnest preparation for the impending response. Neuronal involvement in such preparation could be viewed as an effect of motor program retrieval rather than as participation in program retrieval itself. The instances of progressive increases in response speed during learning might be taken to support that argument. However, such increases are absent for many instances of lcarning-depen-

\section{Table 3. Correlation of activity following familiar versus novel} stimuli

\begin{tabular}{|c|c|c|c|c|}
\hline \multirow{2}{*}{$\begin{array}{l}\text { Activity } \\
\text { pattern }\end{array}$} & \multicolumn{2}{|c|}{$\begin{array}{l}\text { Stimuli (impulses/ } \\
\text { sec } \pm \mathrm{SD} \text { ) }\end{array}$} & \multirow{2}{*}{$\begin{array}{l}\text { Spearman } \\
\text { correlation } \\
\text { coefficient }\end{array}$} & \multirow{2}{*}{$\begin{array}{l}\text { Significance } \\
\text { of } \\
\text { correlation }\end{array}$} \\
\hline & Familiar & Novel & & \\
\hline Signal & $20.5 \pm 10.1$ & $27.5+11.0$ & $\rho=0.68$ & $p<0.05$ \\
\hline Set & $13.7 \pm 10.0$ & $18.6 \pm 10.4$ & $\rho=0.79$ & $p<0.005$ \\
\hline Movement & $23.2 \pm 18.2$ & $17.3 \pm 5.5$ & $\rho=0.98$ & $p<0.0001$ \\
\hline
\end{tabular}

This table shows population statistics for neuronal activity levels (mean \pm SD) for cells with increasing learning-dependent activity (anticipatory activity excluded), Spearman's correlation, and its level of significance. Data for novel stimuli come from periods after the conditional motor association had been learned. 

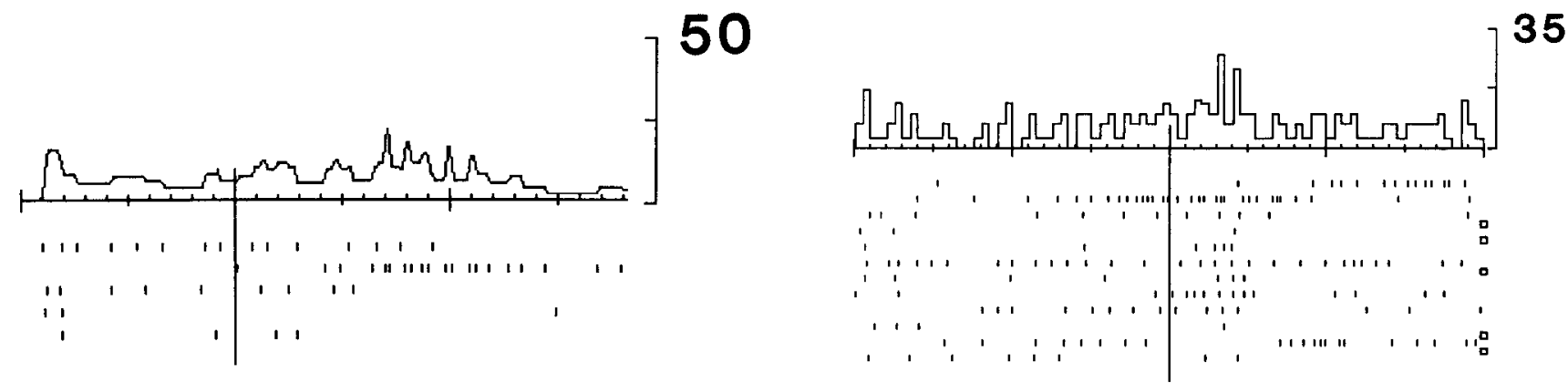

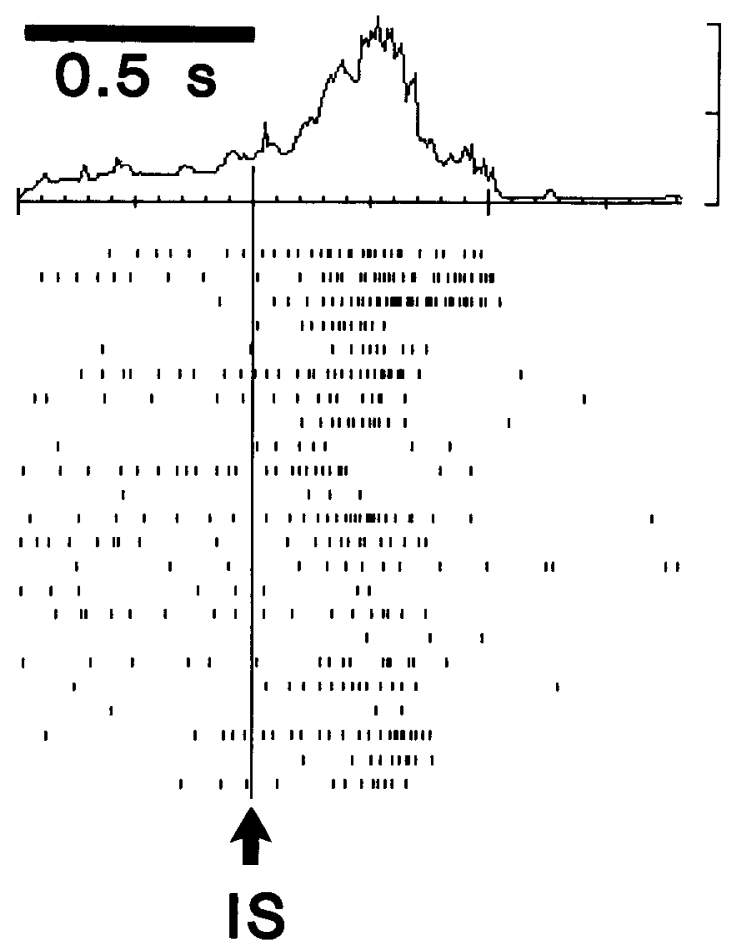

Figure 12. Signal-related PM neuron from the first monkey. Activity displays are aligned on $I S$ onset. Top, The first five correct trials. Bottom, The final 23 correct trials. Activity scale, in impulses/sec, is identical for both RIPs.

dent activity change and, on average, terminated before the neuronal modulation reached its full development. Therefore, a simple interpretation in terms of the lcvel of preparcdncss or response speed seems to us less likely than a role in motor program retrieval.

The present results raise another issue. The fact that many PM cells become task related or greatly increase their taskrelated activity only after the monkey learns a visuomotor association suggests that other cells function in response selection on other bases. Perhaps these other cells are in PM, but it is tempting to speculate that they might be found in the supplementary motor area or other medial motor areas instead. This suggestion is consistent with the idea that medial motor areas play a specialized role in the guidance of behavior based on "internal," nonsensory factors rather than "external," sensory ones (Wise, 1984; Goldberg, 1985; Okano and Tanji, 1987; Passingham, 1987; Passingham et al., 1989; Mushiake et al., 1990).

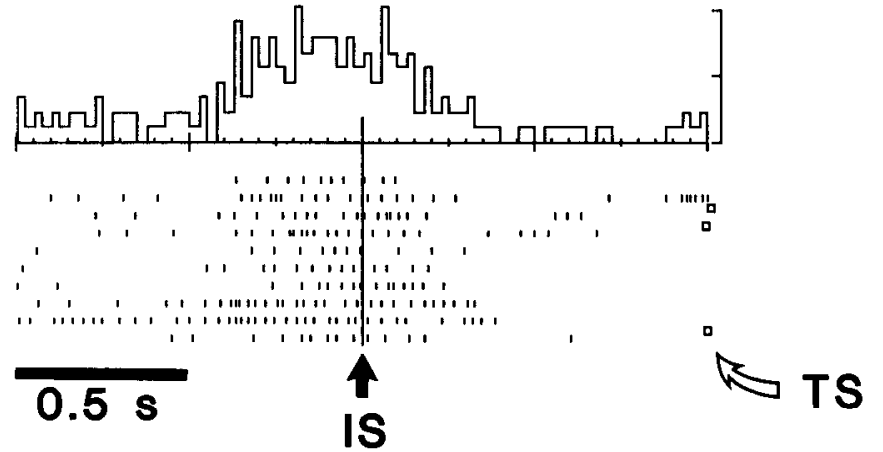

Figure 13. PM neuron with anticipatory discharge, from the first monkey. Format is the same as in Figure 10, except that a histogram (bin width, $25 \mathrm{msec}$ ) is substituted for the RIP. Top. The first 12 correct trials. Bottom, The last 10 correct trials. For trials with the shortest instructed delay periods, the time of the TS is marked by the open squares to the right. Activity scale, in impulses/sec, is identical for both histograms.

\section{Interpretational limitations and problems}

There are two important limitations of the present study. First, the present results do not bear on the mechanism of visuomotor learning; that is, they do not support any attempt to locate synaptic changes that may underlie such learning. Second, there are many types of motor learning, memory, and retrieval, and we have studied only one. We hasten to point out that during recording the monkeys did not learn the movement per se, but rather learned to select the correct, already learned, movement on the basis of arbitrary stimulus-response associations. Other types of motor learning that have been studied in primates include skill acquisition (Gilbert and Thach, 1977; Brooks et al., 1978, 1983; Brooks, 1986; Kennedy and Humphrey, 1987; Sakamoto et al., 1987; Iriki et al., 1989; Wolpaw and Lee, 1989; Wolpaw et al., 1989), adaptive plasticity (Lisberger, 1988), and classical conditioning (Woody, 1986; Thompson, 1987). Furthermore, one must distinguish between learning and retrieving from memory what to do on the basis of environmental cues, and learning when to initiate a movement, for example, upon receipt of a visual signal, as has been studied by Sasaki and Gemba (1981, 1982). The regions and mechanisms underlying these other forms of motor learning, memory, and retrieval may differ from those supporting conditional visuomotor behavior.

Alternative interpretations of the present results involve attention, nonspecific behavioral and temporal factors, and muscle activity. It is possible that presumptive attentional changes during conditional motor learning may account for some of the activity changes observed, but early presentations of a novel 


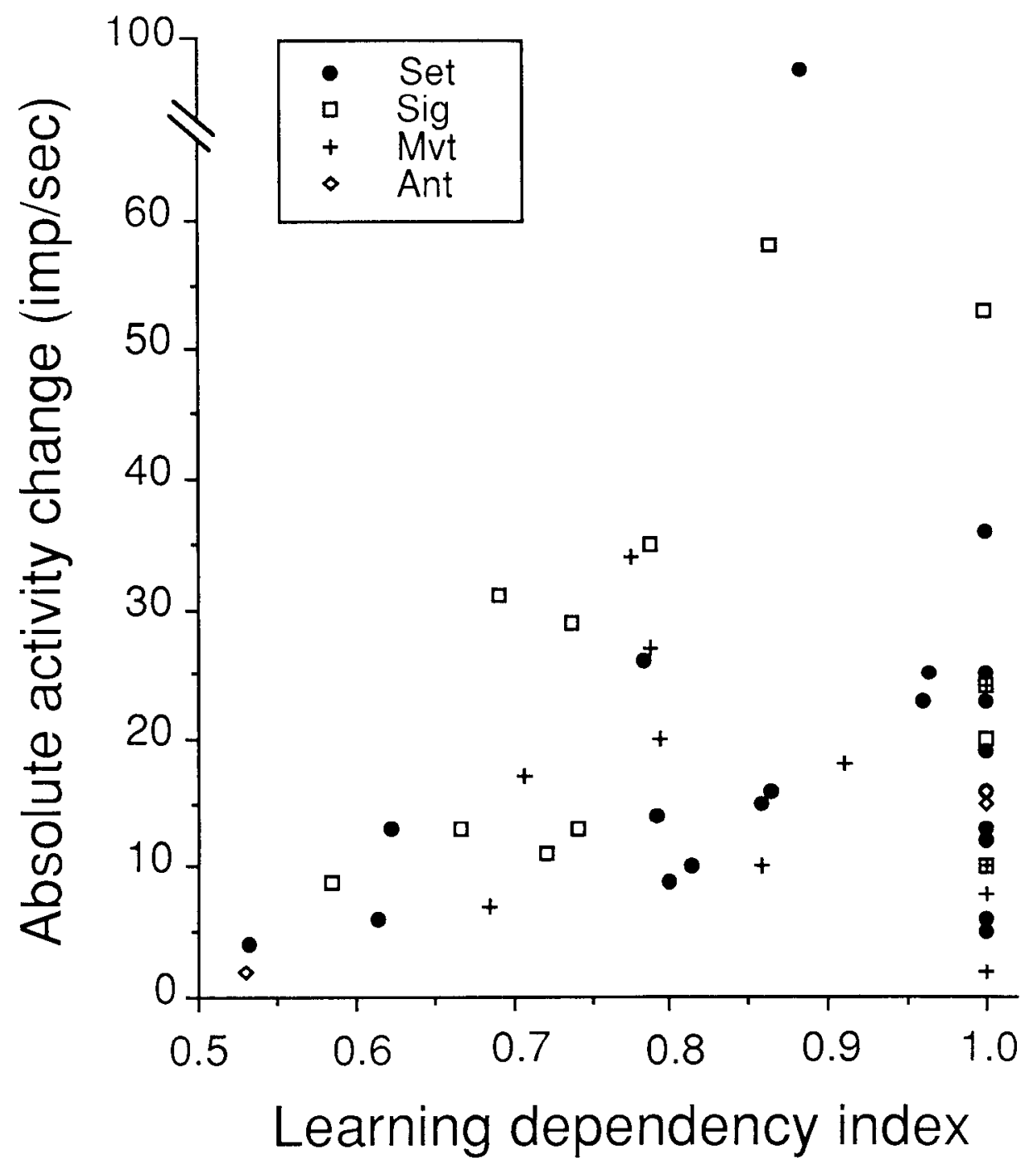

Figure 14. Learning-dependency index versus absolute activity change. Task-related activity for the last correct response minus the first correct response for each novel stimulus (absolute activity change) is plotted against the learning-dependency index (see Materials and Methods). Only neurons with activity that increases during learning are included. Note that a cell can be represented more than once if it has lcarning-dependent changes in different task periods. stimulus, which demanded the most focused attention, were usually associated with lower activity rates. Furthermore, attentional explanations are rendered unlikely by the finding that deficits in conditional motor behavior observed after PM ablation cannot be explained in terms of attentional deficits (Halsband and Passingham, 1985; Petrides, 1986). Nonspecific aspects of behavior, such as arousal, level of motivation, and either the frequency or the expectation of reward, can bc ruled out for neurons showing directional selectivity. A nonspecific temporal interpretation, for example, that the changes in activity reflect the passage of time (or number of trials) rather than learning, is ruled out by observations such as that illustrated in Figure 9, which shows that the change in activity does not occur in the absence of learning. The close correlation between learning rate and the change in activity (Figs. 3, 6, 7) strongly supports the same conclusion. As with any study of this type, it is possible that all results could be accounted for by postulating the existence of some muscle group with which the neuronal activity correlates. Our examination of muscle activity does not support this interpretation, though it cannot be ruled out completely. At least in the first monkey, no EMG record showed significant activity increases during conditional motor learning that resembled the learning-dependent increases in neuronal activity. The argument is weaker for decreases in activity and for the second monkey.

Because we did not monitor or control eye position, an oculomotor interpretation remains conceivable, but insofar as it has been studied to date, neither PM nor M1 appears to have cells related to eye movement or position (Weinrich and Wise, 1982; Weinrich et al., 1984; Godschalk et al., 1985; Mauritz and Wise, 1986; Vaadia et al., 1986). Similarly, the complexity of the stimuli opens the possibility of ad hoc interpretations in terms of visual receptive fields, but PM and other frontal visual receptive fields are large and apparently unselective for the properties of the stimulus (Pigarev et al., 1979; Rizzolatti et al., 1981 b; Gentilucci et al., 1983; Suzuki and Azuma, 1983; Boch and Goldberg, 1989). Further, we tested many cells on several groups of novel stimuli. In each instance, two to eight different visual stimuli instructed a given response, but the characteristic learning-dependent changes in activity were observed regardless of stimulus details. Thus, any interpretation in terms of visual receptive fields seems highly unlikely.

Finally, those cases in which we failed to demonstrate significant learning-dependent changes cannot be interpreted as the absence of such change. Our analysis is likely to have underestimated the number and proportion of such changes by 
Figure 15. Surface reconstruction of sites of penetrations in which learningdependent activity changes were observed, for first monkey. The size of the solid circles indicates the number of lcarning-dependent cells in each penetration (as identified in the key to the right). Open circles indicate penetrations with cells adequately tested, but showing no significant learning-dependent changes. Broken vertical lines indicate cytoarchitectonic boundaries between the indicated areas, with a zone of uncertainty noted by the question mark. Asterisks indicate the sites of electrolytic lesions. Arrows $A-L$ refer to the sections illustrated in Figure 16. Inset, Drawing of hemisphere. $A$, arcuate sulcus; $C$, central sulcus; $M$, medial; $P$, principal sulcus; $R$, rostral; $S P$, superior precentral sulcus.
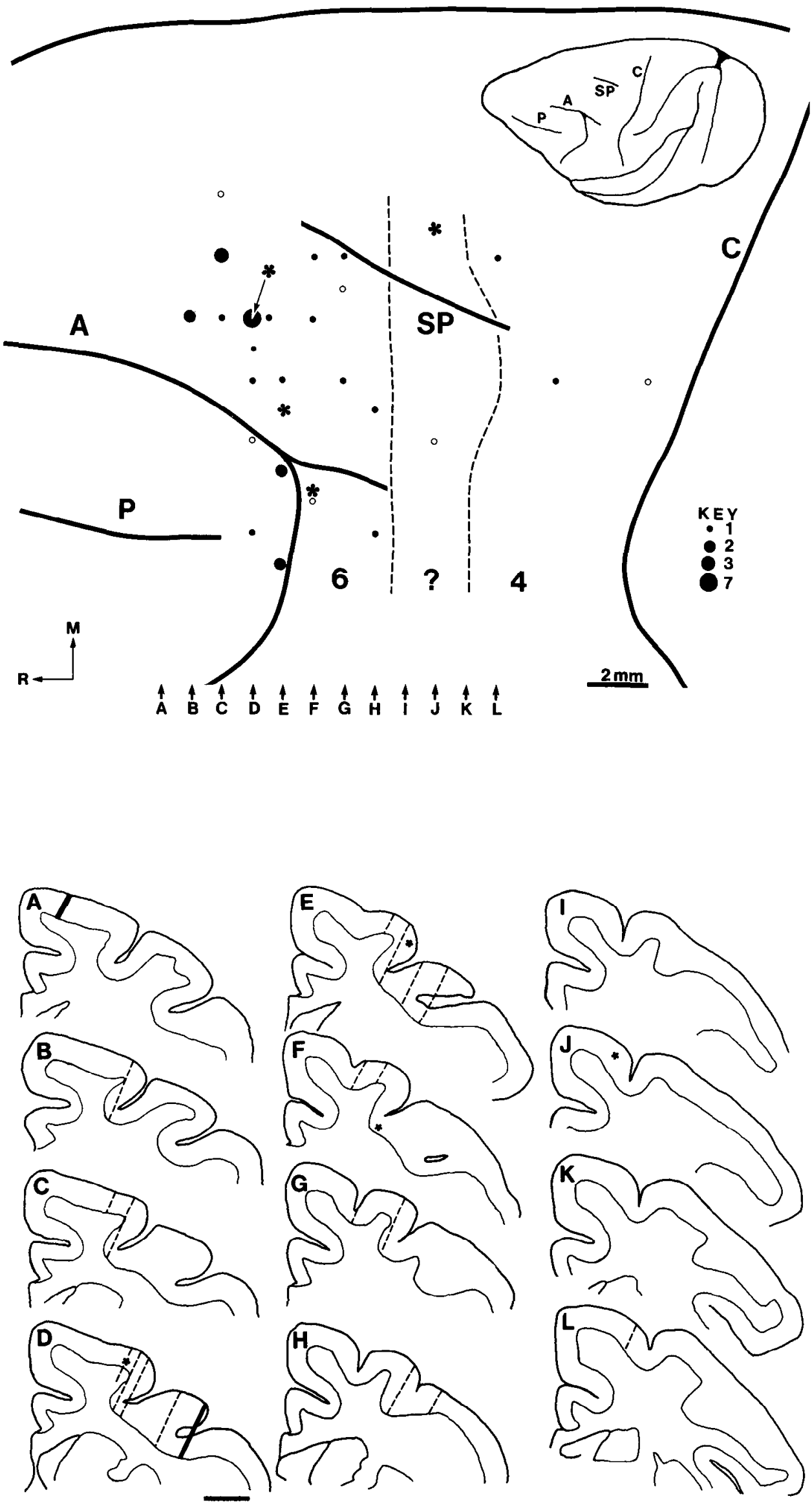

Figure 16. Sections pertaining to the surface reconstruction of Figure 15. Sections $A-L$ show data collapsed from $1 \mathrm{~mm}$ of tissue from the rostrocaudal levels indicated at the bottom of Figure 15. The asterisks indicate the locations of the electrolytic lesions (see Fig. 17); the broken lines show the plotted penetration tracks for penetration in which learning-dependent activity was observed. The solid lines parallel to the penetrations ( $A$ and $D$ ) indicate the locations of pin holes made at known electrode coordinates. Scale bar, $5 \mathrm{~mm}$. 

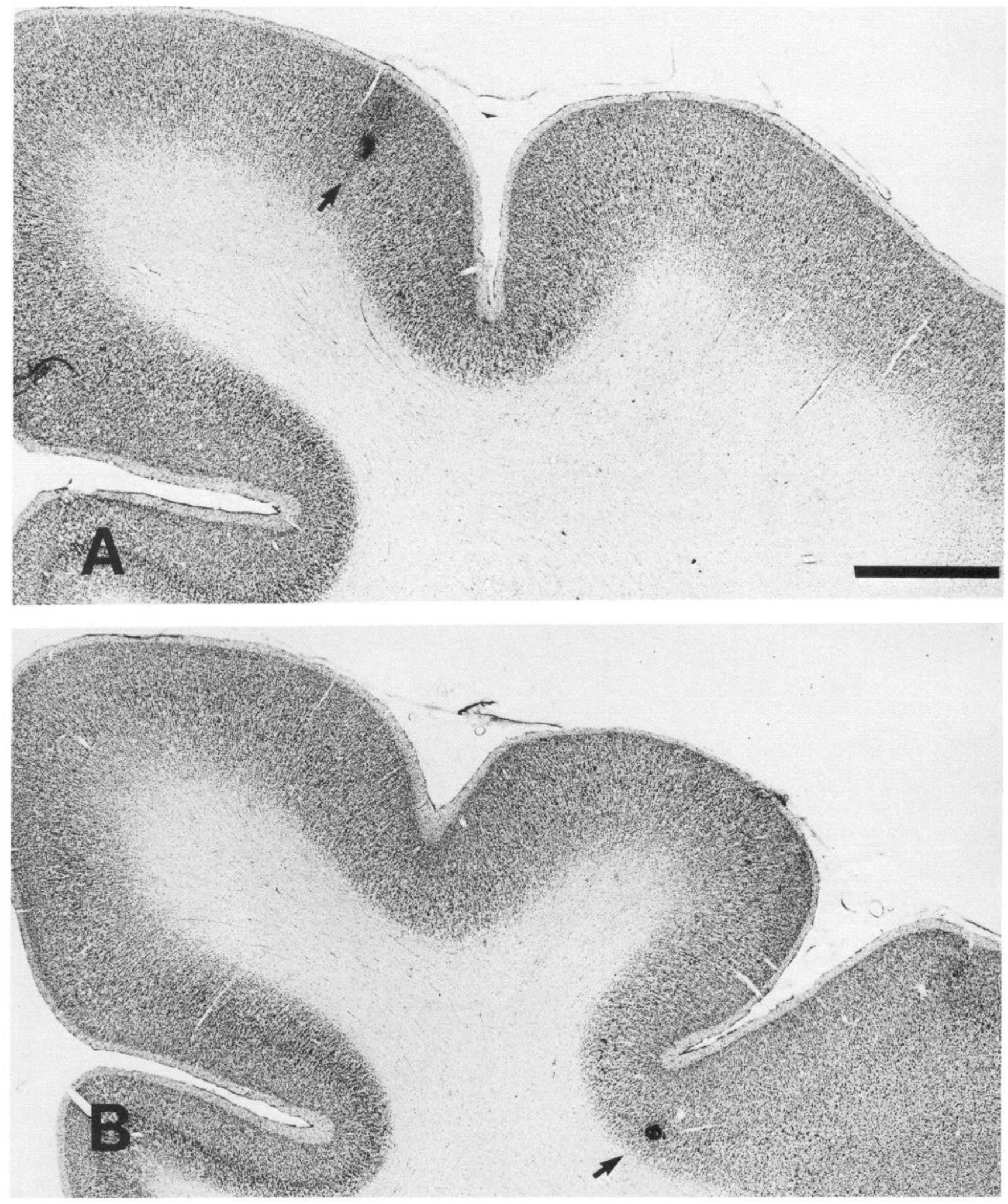

Figure 17. Photomicrographs of Nissl-stained sections. $A$, From Figure $16 J$. B, From Figure $16 F$. Note that these levels can also be related to Figure 15, arrows $F$ and $J$. Arrows point to electrolytic lesions. Scale bar, $2.5 \mathrm{~mm}$. 


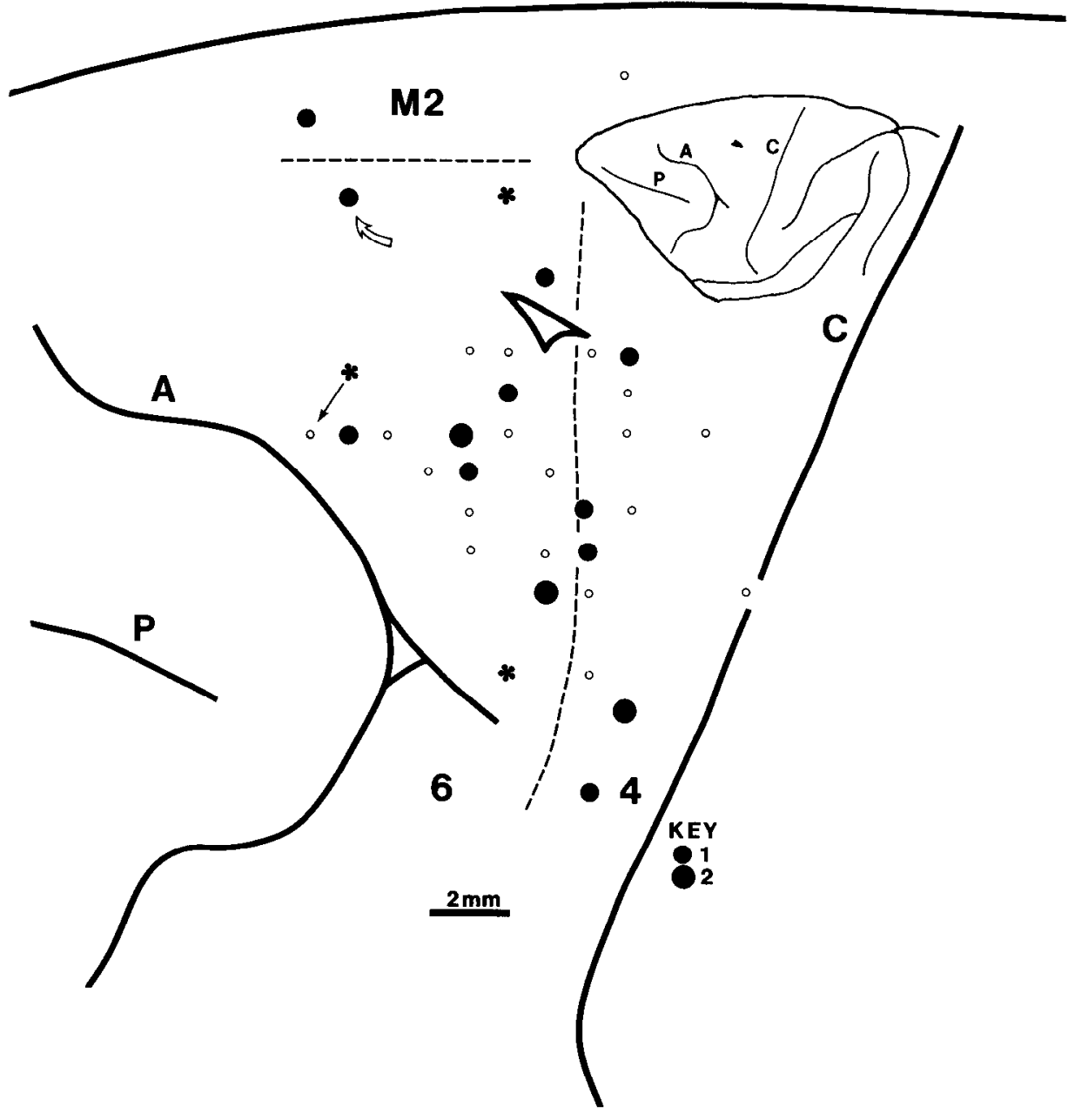

Figure 18. Surface reconstruction for the second monkey in the same format as Figure 15

failing to take into account information encoded in the spike train and by the elimination of cells with changes in the overall (or reference) level of activity.

\section{Neural activity during acquisition of associative memories}

The present article is the first to systematically describe learningdependent activity changes in individual frontal cortex neurons and the first, at the single-cell level, to address the process of movement selection. Kubota and Komatsu (1985) reported an increase in the number of task-related neurons in three separate samples of prefrontal cortex neurons. From these data, they inferred that individual neurons changed their activity during task acquisition. Watanabe (1990) studied three prefrontal cortex cells during the reversal of conditional associations. Niki et al. (1990) have presented some preliminary data similar to those presented here. Outside the frontal cortex, previous studies have revealed learning-dependent changes in neuronal activity, typically in relation to sensory responses. Sensory responses of neurons in the auditory cortex (Diamond and Weinberger, 1989) and amygdala (Ben-Ari, 1972; Ben-Ari and La Salle, 1972) have been observed to change when cats learned to associate sounds with somatic electrical stimulation, and similar activity changes have been observed in visual cortex neurons after a few presentations of novel faces (Rolls et al., 1989). By contrast to sensory learning, the cell properties reported here occur in a motor cortical area and represent, therefore, a level relatively close to the mechanisms by which actions are selected and goals accomplished.

\section{Previous neurophysiological studies of PM}

PM has been the subject of numerous neurophysiological studies, primarily motivated by concepts originating in motor systems research. These studies have in common the recording of neuronal activity while monkeys perform operantly conditioned movements. Almost without exception, the tasks employed can be described as conditional motor tasks, usually conditional visuomotor tasks. That is, one stimulus (either by quality or location) instructs one response, and other stimuli instruct other responses (Kubota and Hamada, 1978; Godschalk et al., 1981; Weinrich and Wise, 1982; Godschalk and Lemon, 1983; Weinrich et al., 1984; Kurata and Tanji, 1986; Vaadia et al., 1986; Amos et al., 1988; Kurata and Wise, 1988a; Tanji et al., 1988; Crammond and Kalaska, 1989; Caminiti et al., 1989, 1990; Karluk and Ebner, 1989; Kurata, 1989; Riehle and Requin, 1989; Hocherman and Wise, 1990). Thus, it is possible that the previous studies of PM, whatever the motivation of the experimental design, all reveal task-related activity because they involve the retrieval from memory of a response based on arbitrary environmental context, that is, conditional motor behavior.

Two data sets are more difficult to describe in terms of conditional motor associations. Kurata and Wise (1988b) found substantial PM activity in a spatial reversal task, which might 
be considered a conditional motor task on the assumption that the presence or absence of reward on a trial instructs the next movement. Okano and Tanji (1987) found PM cells that had roughly equal activity during a visually triggered and self-triggered hand movement. Only one movement was performed, so the task is not conditional in the usual sense. However, the task can be construed as conditional on the argument that the presence of a visual stimulus elicits a rapid response, whereas its absence, at a certain time during the trial, elicits a long-latency response. Finally, other PM data have been interpreted in a manner apparently incompatible with the present thesis (Rizzolatti et al., 1981a-c, 1988; Gentilucci et al., 1988). It is possible, however, that when monkeys are behaving in an open, "clinical" examination of cell activity, they are engaged in occult conditional motor behaviors, perhaps reflecting past experience with receiving reinforcement in such a setting.

\section{Role of cerebellum}

The present data are of interest in view of previous suggestions that the cerebellum plays an important role in at least certain kinds of motor learning (Marr, 1969; Gilbert, 1975; Brooks and Thach, 1981; Brooks, 1984; Ito, 1984). The cerebellum has been implicated in a classically conditioned movement, the nictitating membrane response (Thompson, 1987), in an instance of adaptive plasticity, the vestibulo-ocular reflex (Lisberger, 1988), and in an operantly conditioned motor skill, forelimb force production (Gilbert and Thach, 1977). Furthermore, it has been reported that cerebellar lesions or atrophy leads to relatively specific deficits in conditional associative learning in humans (Bracke-Tolkmitt et al., 1989). These findings, coupled with the report that cerbellothalamocortical inputs form the principal subcortical input to PM (Schell and Strick, 1984), suggest that the cerebellum and PM may operate together as part of a neural network subserving the establishment and retrieval of motor programs.

\section{References}

Amos TM, Vermeersch CH, Park S-K, Ebner TJ (1988) Principle [sic] component analysis of the responses of premotor cortical neurons to movement in two dimensions. Soc Neurosci Abstr 14:343.

Ben-Ari Y (1972) Plasticity at unitary level. I. An experimental design. Electroencephalogr Clin Neurophysiol 32:655-665.

Ben-Ari Y, La Salle G (1972) Plasticity at unitary level. II. Modifications during sensory-sensory association procedures. Electroencephalogr Clin Neurophysiol 32:667-679.

Boch RA, Goldberg ME (1989) Participation of prefrontal neurons in the preparation of visually guided eye movements in the rhesus monkey. J Neurophysiol 61:1064-1084.

Bracke-Tolkmitt R, Linden A, Canavan AGM, Rockstroh B, Scholz E, Wessel K, Diener H-C (1989) The cerebellum contributes to mental skills. Behav Neurosci 103:442-446.

Brooks VB (1984) The cerebellum and adaptive tuning of movements. Exp Brain Res [Suppl] 9:170-183.

Brooks VB (1986) How does the limbic system assist motor learning? A limbic comparator hypothesis. Brain Behav Evol 29:29-53.

Brooks VB, Thach WT (1981) Cerebellar control of posture and movement. In: Handbook of physiology - the nervous system II (Brooks VB, ed), pp 877-946. Bethesda, MD: American Physiological Society.

Brooks VB, Reed DJ, Eastman MJ (1978) Learning of pursuit visuomotor tracking by monkeys. Physiol Behav 21:887-892.

Brooks VB, Kennedy PR, Ross H-G (1983) Movement programming depends on understanding of behavioral requirements. Physiol Behav 31:561-563.

Caminiti R, Johnson PB, Pastore RA, Urbano A (1989) The cortical representation of a coordinate system for the planning and execution of arm movements in space. In: Abstracts of EBBS workshop, Cortical control of sensory-motor integration (Jeannerod M, Joseph JP, eds), p 25. Lyon: European Brain and Behavior Society.

Caminiti R, Johnson PB, Urbano A (1990) Making arm movements within different parts of space: dynamic aspects in the primate motor cortex. J Neurosci 10:2039-2058.

Crammond DJ, Kalaska JF (1989) Comparison of cell activity in cortical areas 6,4 and 5 recorded in an instructed delay task. Soc Neurosci Abstr 15:786.

Crowne DP, Dawson KA, Richardson CM (1989) Unilateral periarcuate and posterior parietal lesions impair conditional position discrimination learning in the monkey. Neuropsychologia 27:1119-1127.

Diamond DM, Weinberger NM (1989) Rolc of context in the expression of learning-induced plasticity of single neurons in auditory cortex. Behav Neurosci 103:471-494.

Gaffan D, Harrison S (1988) Inferotemporal-frontal disconnection and fornix transection in visuomotor conditional learning by monkeys. Behav Brain Res 31:149-163.

Gentilucci M, Rizzolatti G (1989) Cortical motor control of arm and hand movements. In: Vision in action: the control of grasping (Goodale MA, ed), pp 147-162. Norwood, NJ: Ablex.

Gentilucci M, Scandolara C, Pigarev IN, Rizzolatti G (1983) Visual responses in the postarcuate cortex (area 6) of the monkey that are independent of eye position. Exp Brain Res 50:464-468.

Gentilucci M, Fogassi L, Luppino G, Matelli M, Camarda R, Rizzolatti $G$ (1988) Functional organization of inferior area 6 in the macaque monkcy. I. Somatotopy and the control of proximal movements. Exp Brain Res 71:475-490.

Gilbert PFC (1975) How the cerebellum could memorise movements? Nature 254:688-689.

Gilbert PFC, Thach WT (1977) Purkinje cell activity during motor learning. Brain Res 128:309-328.

Godschalk M, Lemon RN (1983) Involvement of monkey premotor cortex in the preparation of arm movements. In: Neuronal coding of motor performance (Massion J, Paillard J, Schultz W, Wiesendanger M, eds), pp 114-119. New York: Springer.

Godschalk M, Lemon RN, Nijs HGT, Kuypers HGJM (1981) Behavior of neurons in monkey peri-arcuate and precentral cortex before and during visually guided arm and hand movements. Exp Brain Res 44:113-116.

Godschalk M, Lemon RN, Kuypers HGJM, van der Steen J (1985) The involvement of monkey premotor cortex neurones in preparation of visually cued arm movements. Behav Brain Res 18:143-157.

Goldberg G (1985) Supplementary motor area structure and function: review and hypotheses. Behav Brain Sci 8:567-616.

Halsband U, Freund H-J (1990) Premotor cortex and conditional motor learning in man. Brain 113:107-222.

Halsband U, Passingham RE (1982) The role of premotor and parietal cortex in the direction of action. Brain Res 240:368-372.

Halsband U, Passingham RE (1985) Premotor cortex and the conditions for movements in monkeys (Macaca fascicularis). Behav Brain Res 18:269-277.

Harlow HF (1949) The formation of learning sets. Psychol Rev 56: $51-65$.

I Iocherman S, Wise SP (1990) Trajectory-selective neuronal activity in the motor cortex of rhesus monkeys. Behav Neurosci 104:495499.

Humphrey DR (1979) On the cortical control of visually directed reaching: contributions by nonprecentral motor areas. In: Posture and movement (Talbot RE, Humphrey DR, eds), pp 51-112. New York: Raven.

Iriki A, Pavlides C, Keller A, Asanuma H (1989) Long-term potentiation in the motor cortex. Science 245:1385-1387.

Ito M (1984) The cerebellum and neural control. New York: Raven.

Karluk D, Ebner TJ (1989) Spatial representation of movement distance and direction in the premotor cortex. Soc Neurosci Abstr 15: 787.

Kennedy PR, Humphrey DR (1987) The compensatory role of the parvocellular division of the red nucleus in operantly conditioned rats. Neurosci Res 5:39-62.

Kubota K, Hamada I (1978) Visual tracking and neuron activity in the postarcuate area in monkeys. J Physiol (Paris) 74:297-312.

Kubota K, Komatsu H (1985) Neuron activities of monkey prefrontal cortex during the learning of visual discriminations tasks with $\mathrm{GO}$ / NO-GO performances. Neurosci Res 3:106-129.

Kurata K (1989) Motor programming in premotor cortex of the mon- 
keys. In: Taniguchi symposia on the brain sciences, No 12, Neural programming (Ito M, ed), pp 39-47. Tokyo: Japan Scientific Societies; Basel: Karger.

Kurata K, Tanji J (1986) Premotor cortex neurons in macaques: activity before distal and proximal forelimb movements. J Neurosci 6 : 403-411.

Kurata K, Wise SP (1988a) Premolor cortex of rhesus monkeys: setrelated activity during two conditional motor tasks. Exp Brain Res 69:327-343.

Kurata K, Wise SP (1988b) Premotor and supplementary motor cortex in rhesus monkeys: neuronal activity during externally- and internally-instructed motor tasks. Exp Brain Res 72:237-248.

Lisberger SG (1988) The neural basis for learning of simple motor skills. Science 241:728-735.

Marr D (1969) A theory of cerehellar cortex. J Physiol (I ond) 202: $437-470$.

Mauritz K-H, Wise SP (1986) Premotor cortex of the rhesus monkey: neuronal activity in anticipation of predictable environmental events. Exp Brain Res 61:229-244.

Mitz AR, Wise SP, Godschalk M (1989) Learning-dependent activity in premotor corlex of rhesus monkeys. Soc Neurosci Abstr 15:787.

Mushiake H, Inase M, Tanji J (1990) Selective coding of motor sequence in the supplementary motor area of the monkey cerebral cortex. Exp Brain Kes 82:208-210.

Niki H, Sugita S, Watanabe M (1990) Modification of the activity of primate frontal neurons during learning of a go/no-go discrimination and its reversal. A progress report. In: Vision, memory and the temporal lobe (Iwai E, Mishkin M, eds), pp 295-304. New York: Elsevier.

Okano K, Tanji J (1987) Neuronal activities in primate motor fields of the agranular frontal cortex preceding visually triggered and selfpaced movement. Exp Brain Res 66:155-166.

Passingham RE (1987) Two cortical systems for directing movement. In: Ciba Foundation symposium 132, Motor areas of the cerebral cortex (Bock G, O'Connor M, Marsh J, eds), pp 151-164. Chichester: Wiley.

Passingham RE (1988) Premotor cortex and preparation for movement. Exp Brain Res 70:590-596.

Passingham RE (1989) Premotor cortex and the retrieval of movement. Brain Behav Evol 33:189-192.

Passingham RE, Chen Y, Thaler D (1989) Supplementary motor cortex and self-initiated movement. In: Taniguchi symposia on the brain sciences, No 12, Neural programming (Ito M, ed), pp 13-24. Tokyo: Japan Scientific Societies; Basel: Karger.

Petrides M (1982) Motor conditional associative-learning after selective prefrontal lesions in the monkey. Behav Brain Res 5:407-413.

Petrides M (1985a) Deficits on conditional associative-learning tasks after frontal- and temporal-lobe lesions in man. Neuropsychologia 23:601-614.

Petrides M (1985b) Deficits in non-spatial conditional associative learning after periarcuate lesions in the monkey. Behav Brain Res 16: 94-101.

Petrides M (1986) The effect of periarcuate lesions in the monkey on the performance of symmetrically and asymmetrically reinforced visual and auditory go, no-go tasks. J Neurosci 6:2054-2063.

Petrides M (1987) Conditional learning and the primate frontal cortex. In: The frontal lobes revisited (Perecman E, ed), pp 91-108. New York: IRBN.

Pigarev IN, Rizzolatti G, Scandolara C (1979) Neurons responding to visual stimuli in the frontal lobe of macaque monkeys. Neurosci Lett 12:207-212.

Riehle A, Requin J (1989) Monkey primary motor and premotor cortex: single-cell activity related to prior information about direction and extent of an intended movement. J Neurophysiol 61:534-549.

Rizzolatti G, Scandolara C, Matelli M, Gentilucci M (1981a) Afferent properties of periarcuate neurons in macaque monkeys. 1. Somatosensory responses. Behav Brain Res 2:125-146.

Rizzolatti G, Scandolara C, Matelli M, Gentilucci M (1981b) Afferent properties of periarciate neurons in macaque monkeys. 2. Visual responses. Behav Brain Res 2:147-163.

Rizzolatti G, Scandolara C, Matelli M, Gentilucci M, Camarda R (1981c) Response properties and behavior modulation of 'mouth' neurons of the postarcuate cortex (area 6 ) in macaque monkeys. Brain Res 255:421-424.

Rizzolatti G, Camarda R, Fogassi L, Gentilucci M, Luppino G, Matelli $M$ (1988) Functional organization of inferior area 6 in the macaque monkey. II. Area F5 and the control of distal movements. Exp Brain Res 71:491-507.

Rolls ET, Baylis GC, Hasselmo ME, Nalwa V (1989) The effect of learning on the face selective responses of neurons in the cortex in the superior temporal sulcus of the monkey. Exp Brain Res 76:153164.

Sakamoto T, Porter LL, Asanuma H (1987) Long-lasting potentiation of synaptic potentials in the motor cortex produced by stimulation of the sensory cortex in the cat: a basis of motor learning. Brain Res 413:360-364.

Sasaki K, Gemba H (1981) Changes of premovement field potentials in the cerebral cortex during learning processes of visually initiated hand movements in the monkcy. Ncurosci Lett 27:125-130.

Sasaki K, Gemba H (1982) Development and change of cortical field potentials during learning processes of visually initiated hand movements in the monkey. Exp Brain Res 48:429-437.

Schell GR, Strick PL (1984) The origin of thalamic inputs to the arcuate premotor and supplementary motor areas. J Neurosci 4:539560.

Suzuki H, Azuma M (1983) Topographic studies on visual neurons in the dorsolateral prefrontal cortex of the monkey. Exp Brain Res 53:47-58.

Tanji J, Okano K, Sato KC (1988) Neuronal activity in cortical motor areas related to ipsilateral, contralateral and bilateral digit movements of the monkey. J Neurophysiol 60:325-343.

Thompson RF (1987) The neurobiology of learning and memory. Science 233:941-948.

Vaadia E, Benson DA, Hienz RD, Goldstein MH (1986) Unit study of monkey frontal cortex: active localization of auditory and of visual stimuli. J Neurophysiol 56:934-952.

Vaadia E, Kurata K, Wise SP (1988) Neuronal activity preceding directional and nondirectional cues in the premotor cortex of rhesus monkeys. Somat Motor Res 6:207-230.

Watanabe M (1990) Prefrontal unity activity during associative learning in the monkey. Exp Brain Res 80:296-309.

Weinrich M, Wise SP (1982) The premotor cortex of the monkey. J Neurosci 2:1329-1345.

Weinrich M, Wise SP, Mauritz K-H (1984) A neurophysiological analysis of the premotor cortex of the monkey. Brain 107:385-414.

Wiesendanger M (1981) Organization of secondary motor areas of cerebral cortex. In: Handbook of physiology, the nervous system (Brooks VB, ed), pp 1121-1147. Bethesda, MD: American Physiological Society.

Wise SP (1984) The nonprimary motor cortex and its role in the cerebral control of movement. In: Dynamic aspects of neocortical function (Edelman G, Cowan WM, Gall E, eds), pp 525-555. New York: Wiley.

Wise SP (1985a) The primate premotor cortex fifty years after Fulton. Behav Brain Res 18:79-88.

Wise SP (1985b) The primate premotor cortex: past, present, and preparatory. Annu Rev Neurosci 8:1-19.

Wise SP (1989) Frontal cortex activity and motor set. In: Taniguchi symposia on the brain sciences, No 12, Neural programming (Ito M, ed), pp 25-38. Tokyo: Japan Scientific Societies; Basel: Karger.

Wise SP, Mauritz K-H (1985) Sct-rclated neuronal activity in the premotor cortex of rhesus monkeys: effects of changes in motor set. Proc R Soc Lond [Biol] 223:331-354.

Wolpaw JR, Lee CL (1989) Memory traces in primate spinal cord produced by operant conditioning of H-reflex. J Neurophysiol 61 : 563-572.

Wolpaw JR, Carp JS, Lee CL (1989) Memory traces in spinal cord produced by $\mathrm{H}$-reflex conditioning: effects of post tetanic potentiation. Neurosci Lett 103:113-119.

Woody CD (1986) Understanding the cellular basis of memory and learning. Annu Rev Psychol 37:433-493. 